\title{
Language Processing Modulated by Literacy: A Network Analysis of Verbal Repetition in Literate and Illiterate Subjects
}

\author{
Karl Magnus Petersson
}

Karolinska Institute, Sweden

\author{
Alexandra Reis \\ Karolinska Institute, Sweden and Hospital de Santa Maria, Portugal \\ Simon Askelöf \\ Karolinska Institute, Sweden
}

Alexandre Castro-Caldas

Hospital de Santa Maria, Portugal

Martin Ingvar

Karolinska Institute, Sweden

\begin{abstract}
Previous behavioral and functional neuroimaging data indicate that certain aspects of phonological processing may not be acquired spontaneously, but are modulated by learning an alphabetic written language, that is, learning to read and write. It appears that learning an alphabetic written language modifies the auditory-verbal (spoken) language processing competence in a nontrivial way. We have previously suggested, based on behavioral and functional neuroimaging data, that auditory-verbal and written language interact not only during certain language tasks, but that learning and developing alphabetic written language capacities significantly modulates the spoken language system. Specifically, the acquisition of alphabetic orthographic knowledge has a modulatory influence on sublexical phonological processing and the awareness of sublexical phonological structure. We have suggested that developing an orthographic representation system for an alphabetic written language, and integrating a phonemegrapheme correspondence with an existing infrastructure for auditory-verbal language processing, will result in a modified language network. Specifically, we suggest that the parallel interactive processing characteristics of the underlying language-processing brain network differ in literate and illiterate subjects. Therefore, the pattern of interactions between the regions of a suitably defined large-scale functional-anatomical network for language processing will differ between literate and illiterate subjects during certain language tasks. In order to investigate this hypothesis further, we analyzed the observed covariance structure in a PET data set from a simple auditory-
\end{abstract}

verbal repetition paradigm in literate and illiterate subjects, with a network approach based on structural equation modeling (SEM). Based on a simple network model for language processing, the results of the present network analysis indicate that the network interactions during word and pseudoword repetition in the illiterate group differ, while there were no significant differences in the literate group. The differences between the two tasks in the illiterate group may reflect differences in attentional modulation of the language network, executive aspects of verbal working memory and the articulatory organization of verbal output. There were no significant differences between the literate and illiterate group during word repetition. In contrast, the network interactions differed between the literate and illiterate group during pseudoword repetition. In addition to differences similar to those observed in the illiterate group between word and pseudoword repetition, there were differences related to the interactions of the phonological loop between the groups. In particular, these differences related to the interaction between Broca's area and the inferior parietal cortex as well as the posterior-midinsula bridge between Wernicke's and Broca's area. In conclusion, the results of this network analysis are consistent with our previously presented results and support the hypothesis that learning to read and write during childhood influences the functional architecture of the adult human brain. In particular, the basic auditory-verbal language network in the human brain is modified as a consequence of acquiring orthographic language skills. 


\section{INTRODUCTION}

Several cognitive models for language processing have been constructed based on clinical and experimental evidence (e.g., Patterson \& Shewell, 1987; Patterson \& Lambon Ralph, 1999; Caplan, 1992). In most cognitive models of language, written language constitutes a set of parallel processes interacting with auditory-verbal language at different levels. We have previously suggested, based on behavioral (Reis \& Castro-Caldas, 1997) and functional neuroimaging data (Castro-Caldas, Petersson, Reis, Stone-Elander, \& Ingvar, 1998), the auditory-verbal and written language interact not only during certain language tasks, but that learning and developing alphabetic written language capacities significantly modulates the auditory-verbal language system. Additional support for this hypothesis are data indicating interhemispheric differences in the posterior parietal cortex related to literacy (Petersson, Reis, Askelöf, Castro-Caldas, \& Ingvar, 1998). These differences are paralleled by morphological findings indicating that the part of corpus callosum relaying the interhemispheric connections between the left and right posterior parietal cortices is different in literate and illiterate subjects (Castro-Caldas et al., 1999). Taken together these data suggest that learning an alphabetic written language influences auditory-verbal language in a nontrivial way. However, it is still unclear which processes and mechanisms mediate this modulatory influence and which parts of the language system or which processing levels are affected.

To investigate the functional organization of language, and in particular the modulatory influence of literacy on language processing, we have chosen to study natural illiteracy (Castro-Caldas, Reis, \& Guerreiro, 1997; CastroCaldas et al., 1998; Castro-Caldas et al., 1999; Petersson et al., 1998; Petersson, Reis, Castro-Caldas, \& Ingvar, 1999c; Reis \& Castro-Caldas, 1997). Specifically, subjects are classified as illiterate when they, for social reasons, have never received any literacy training. The subjects have never attended school or received any other form of training in and have no knowledge of reading or writing. All subjects, literate and illiterate, are recruited from a similar socio-cultural background in a homogeneous fishermen community in southern Portugal. The subjects are actively working and fully participating in their community and in other respects are considered normal. In this context, it is important to distinguish between natural and functional illiteracy. Functional illiterates have received literacy training, but lost the ability to read and write due to lack of practice. Previous exposure to written language learning and the acquisition of phonemic-graphemic associations implies the existence (or at least a residual) of a visuo-graphic representation system. In contrast, (naturally) illiterate subjects lack orthographic knowledge and a visuo-graphic representation system for language as well as an explicit awareness of sublexical segmentation.
There are several reasons for a general network approach to the understanding of brain function, including the neuroanatomic organization of the brain itself. The organization of the brain resembles a hierarchically structured, recurrently connected network composed of different brain areas, consisting of several types of neurons and synaptic connections with different processing properties (Shepherd, 1997; Felleman \& Van Essen, 1991). Generally, information is thought to be represented as distributed activity in the brain and information processing, subserving complex cerebral functions, are hypothesized to emerge from the interactions between different functionally specialized regions or neuronal groups (Mesulam, 1998; Arbib, 1995; Macdonald \& Macdonald, 1995; Koch \& Davis, 1994; Mesulam, 1990; Amit, 1989). Independent of whether the net result is serial symbolic processing (Fodor \& Pylyshyn, 1990) or parallel subsymbolic processing (Macdonald \& Macdonald, 1995; Smolensky, 1988), at one level or another cerebral functions are implemented in the network architecture of the brain. A network approach is therefore natural when trying to describe brain functions. In particular, analyzing the dynamic patterns of interaction between different functionally specialized brain regions or neuronal assemblies should contribute to the understanding of sensorimotor and cognitive functions (Ingvar \& Petersson, 2000). It has been suggested that three different language pathways (or processing networks) may be engaged in verbal repetition: the semantic, the lexical, and the phonological route. These networks are active during language processing and may operate as subsystems in a structured network for parallel, distributed, and interactive processing (Castro-Caldas et al., 1998; see further Seidenberg \& McClelland, 1989; Seidenberg, 1995; Caplan, 1992; Martin \& Saffran, 1992; Patterson \& Shewell, 1987; and also Pinker \& Prince, 1989; Pinker, 1997; Prince \& Smolensky, 1997; Redington \& Chater, 1997; Snowling, Hulme, \& Nation, 1997; Shastri, 1995; Shastri \& Ajjanagadde, 1993; Rumelhart \& McClelland, 1986). We have suggested that developing an orthographic representation system for an alphabetic written language, integrating a phoneme-grapheme correspondence with an existing infrastructure for auditory-verbal (spoken) language processing, will result in a modified language network. Specifically, we suggest that the parallel interactive processing characteristics of the underlying language-processing system of the brain differ in literate and illiterate subjects. Therefore, the pattern of interactions between the regions of the large-scale functional-anatomical network (for a review see Mesulam, 1990; Mesulam, 1998) for language processing will differ between literate and illiterate subjects during certain language tasks. In particular, we hypothesize that the network interactions during word and pseudoword repetition is different in the illiterate group, but more similar in the literate group. 
In everyday conversations, spoken language appears similar in literate and illiterate subjects. However, closer examination reveals that the groups differ when tested on several language tasks, in particular if awareness of the phonological structure of words is required to solve the task (Castro-Caldas et al., 1998; Reis \& Castro-Caldas, 1997; Adrian, 1993; Morais, Cary, Alegria, \& Bertelson, 1979; Morais, 1993). Some of these differences appear to be related to aspects of sublexical phonological processing and the explicit awareness of sublexical structure. In order to further investigate the hypothesis that the pattern of interactions in the language processing network differ between literate and illiterate subjects, we analyzed the covariance structure or functional connectivity (Friston, Frith, Liddle, \& Frackowiak, 1993; Friston, 1994; Aertsen, Gerstein, Habib, \& Palm, 1989; Aertsen \& Preissl, 1991) of our previously reported PET data (Castro-Caldas et al., 1998). We used a network analysis approach based on structural equation modeling (SEM) (McIntosh \& Gonzalez-Lima, 1991; McIntosh \& Gonzalez-Lima, 1994; McIntosh et al., 1994; Horwitz \& McIntosh, 1993; Bollen, 1989; Hayduk, 1987) in conjunction with a simple network model for language processing including simple models for attentional modulation and verbal working memory. In the following section, we briefly describe the basis for the functional-anatomical network model that we used in this study.

\section{Verbal Working Memory}

Verbal repetition engages verbal working-memory processes (Gathercole \& Baddeley, 1993). Repetition of both words and pseudowords have been used when testing the language capabilities of brain-damaged subjects (e.g., Glosser, Kohn, Friedman, Sands, \& Grugan, 1997; Costlett, Roeltgen, Rothi, \& Heilman, 1987) and to investigate different mechanisms involved in language processing of normal subjects (e.g., Patterson \& Shewell, 1987; Patterson \& Lambon Ralph, 1999; Caplan, 1992). Pseudoword repetition, that is, repeating phonologically plausible sequences of phonemes lacking lexico-semantic representation may be used to test phonological processing relatively independent (or at least less dependent) of lexico-semantic processing. When repeating pseudowords, the language system is confronted with new phonological sequences that are stored in the phonological loop until the articulatory output sequence is organized and executed. In contrast to wellknown words, which can access the lexico-semantic system directly and can be analyzed as a whole, pseudowords have to be correctly parsed into phonemes or other sublexical units (input phonology) in order to correctly organize the articulatory output sequence (output phonology) and to be correctly repeated. It should be noted that the ability to correctly repeat pseudowords has also been related to the capacity of the verbal short-term working memory (Gathercole \&
Baddeley, 1993; Gathercole \& McCarthy, 1994; Gathercole, Willis, Baddeley, \& Emslie, 1994).

The Baddeley-Hitch model of verbal working memory (Baddeley, 1992) include a phonological store for holding phonologically coded information on-line and an articulatory control process based on inner speech that can update the information in the phonological store. The phonological loop (the phonological store + the articulatory control process) is behaviorally the most well characterized component of the verbal working memory (Baddeley, 1997). Recently, it was suggested that the verbal working memory has an important functional role as a language learning device during language acquisition (Baddeley et al., 1998). The difference in performance when repeating pseudowords between literates and illiterates (Castro-Caldas et al., 1998; Reis \& Castro-Caldas, 1997) may indicate that the acquisition of written language modulates the phonological loop or other components of verbal working memory.

As an additional prelude to the construction of the functional-anatomical language network, we review some additional functional neuroimaging and anatomical data. Functional neuroimaging data (Paulesu, Frith, \& Frackowiak, 1993; replicated in Paulesu et al., 1996 and Salmon et al., 1996) indicate that the phonological loop is subserved by the posterior third of the superior temporal (Wernicke's area, BA 22), the inferior frontal (Broca's area, BA 44/6), and the inferior parietal (BA 39/ 40) cortices as well as the insula. In particular, it has been hypothesized (Paulesu et al., 1993) that the phonological store is related to the inferior parietal region (Démonet, Price, Wise, \& Frackowiak, 1994) while the articulatory control process is related to Broca's area. In addition, it has been suggested that Wernicke's and Broca's areas subserve different aspects of phonological processing (Paulesu et al., 1996). Wernicke's area is thought to subserve auditory word form or input phonology (Paulesu et al., 1996; Démonet et al., 1992), while Broca's area subserves segmented output phonology (Price, Moore, Humphreys, \& Wise, 1997; Démonet, Fiez, Paulesu, Petersen, \& Zatorre, 1996; Paulesu et al., 1996). Furthermore, results from PET activation studies indicate that both irregular (compared to regular words) and nonword reading (compared to regular and irregular words) activate inferior frontal regions (Herbster, Mintun, Nebes, \& Becker 1997). These activations may be related to processes that generate articulatory representations and finally verbal output. Consistently, a task minimizing semantic and maximizing phonological processing activated inferior parietal and left precentral/ inferior frontal region (Price et al., 1997). Functional neuroimaging studies have also indicated that some central executive aspects of verbal working memory are localized to the left middle-inferior prefrontal cortex (BA 45/46) (D'Esposito et al., 1995; Petrides, Alivisatos, Meyer, \& Evans, 1993; Petrides, 1995; Petrides, Alivisatos, \& Evans, 1995). 
It has been hypothesized that the posterior insula may be a neural relay for language (Mesulam \& Mufson, 1985), in particular that automatic language processing is relayed via the insula (Raichle, 1994; Raichle et al., 1994; see also the neurological models of language in Posner \& Raichle, 1994, in particular the dual-pathway model for word generation). This suggestion is consistent with PET data indicating that activation of the posterior insula is associated with repetition of words under conditions minimizing semantic processing and with the development of automaticity in learning a language task (Raichle, 1994; Raichle et al., 1994; Petersen, Fox, Posner, Mintun, \& Raichle, 1989; Petersen \& Fiez, 1993). Furthermore, additional PET data indicate that the insula may mediate interaction between the (left) inferior parietal region and Broca's area (Paulesu et al., 1996). Some clinical evidence also indicate that lesions of the left insula can cause conduction aphasia in which the translation from heard, read or self-generated words into appropriate phonemic sequences is defect (Damasio \& Damasio, 1980).

Most of the cortical and subcortical connections of the insula are reciprocal. The anterior-midinsular connections include inferotemporal, temporopolar, and medial temporal cortices. The anterior and midcingulate cortices connect most prominently to the midportion of the insular cortex, while the posterior-midinsular connections include inferotemporal, cingulate, and prefrontal cortices (Mesulam \& Mufson, 1985). In addition, the posterior-midinsula receives projections from the posterior auditory association area of the superior temporal gyrus and sends projections to the opercular paramotor cortex (Mesulam \& Mufson, 1985). There are also widespread intrainsular connections, which strongly interconnect the various sectors of the insular regions (Mesulam \& Mufson, 1985).

\section{Word and Pseudoword Repetition in Literate and Illiterate Subjects}

The results of our previously reported PET study (Castro-Caldas et al., 1998) comparing literate and illiterate subjects repeating words and pseudowords are briefly summarized here (Figure 1). In the word versus pseudoword comparison, there were similar bilateral activations in the posterior parietal regions (BA 7, 19, 39) in both groups, with a greater left-sided posterior parietal dominance in the literate compared to the illiterate group. In the literate group, posterior midline activations were limited to the right posterior cingulate cortex (BA 23), and in the illiterate group, the precuneate region (BA 7 , 31) extending into posterior cingulate region (BA 23) was activated. In the literate group there were also activations in the left superior and middle frontal region $(\mathrm{BA} 8,9)$, in the right posterior parieto-occipito-temporal region (BA 39, 37, 19), and left occipitotemporal region (BA 19, 37). When thresholding at a

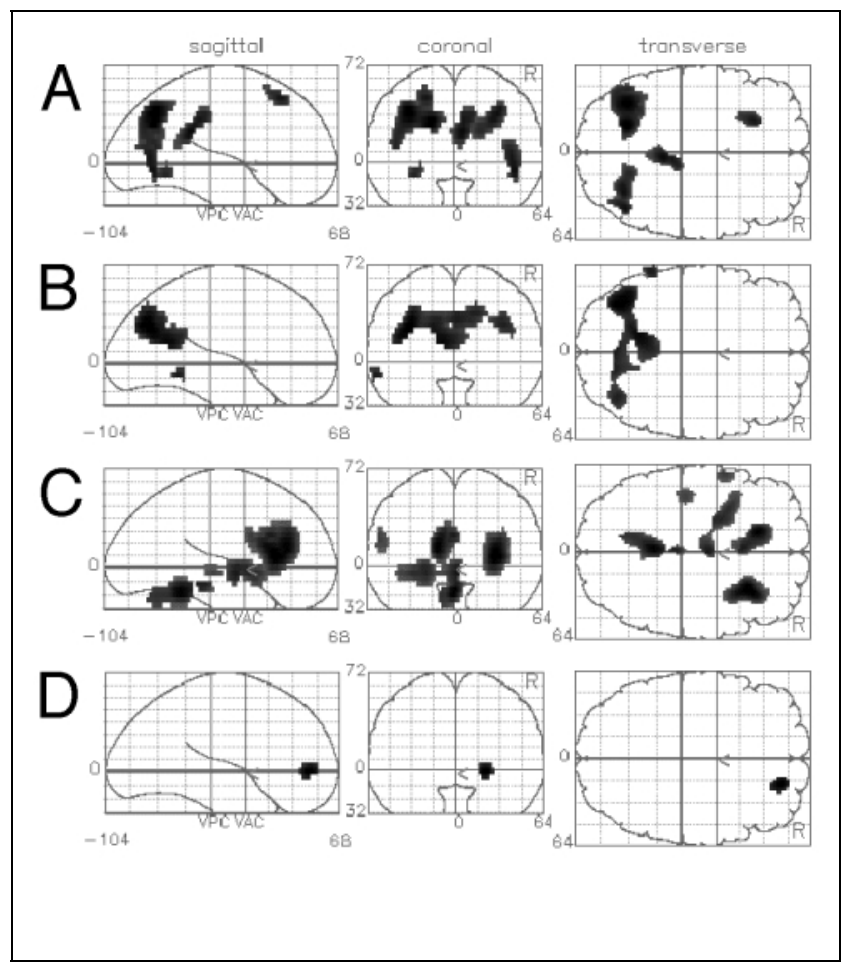

Figure 1. Maximum intensity projections of the SPM $[Z]$ thresholded at $Z=2.58$ (omnibus significance $p \leq .005$ ) in the words-pseudowords contrast in the literate (A) and in the illiterate (B) groups. The reverse contrast (pseudowords-words) in the literate (C) and in the illiterate (D) groups. For further details and results see Castro-Caldas et al. (1998).

lower level in word versus pseudoword comparison, the pattern of activation in literates and illiterates tended to converge toward similar patterns. The only activation in words versus pseudowords that was significantly greater in the literate than in the illiterate group was the more prominent left inferior parietal activation (BA 40).

In the reverse comparison (pseudoword vs. word), the literate group displayed a significant activation in the anterior insular (BA 14, 15) bilaterally and right inferior frontal/frontal opercular (BA 44, 45, 47, 49), left anterior cingulate cortices (BA 24, 32), as well as subcortical structures, including left basal ganglia (putamen, globus pallidus extending into head of caudate nucleus) and midline cerebellum. In the illiterate group, significant activation was only seen in the middle frontal/frontopolar region (BA 10). In general, the interaction analysis confirmed these findings.

The behavioral results showed that the illiterate subjects performed pseudoword repetition less well than the literate subjects (Castro-Caldas et al., 1998; Reis \& Castro-Caldas, 1997). In this context, it should be emphasized that all subjects only produced words or pseudowords and no other type of speech was produced during the PET scanning. When subjects failed to repeat a pseudoword correctly, they still repeated a pseudoword (except for some lexico-semantic analogies, 
Table 1. Group Specific Differences in Activation Patterns (A) in Words versus Pseudowords and (B) Pseudowords versus Words. Anatomical structures and Brodmann's areas (BA) refer to the Talairach and Tournoux (1988) atlas except when indexed * referring to the Karolinska Computerized Brain Atlas of Greitz (Greitz et al. 1991). Local $Z$ score maxima with $Z>2.58(p<.005$, uncorrected $)$ are reported. For further details and more results see Castro-Caldas et al. (1998).

\begin{tabular}{lll}
\hline Region & Z score & [xyz] \\
\hline
\end{tabular}

(A) Greater activation in literates compared to illiterates in words versus pseudowords

Left frontal operculum/anterior insula region, BA 47/49*/14*

$\begin{array}{lllll}\text { With performance covariate } & 2.64 & -30 & 30 & 0\end{array}$

Left inferior/superior parietal region, BA 40

$\begin{array}{lllll}\text { With performance covariate } & 3.22 & -44 & -28 & 40 \\ & 2.90 & -36 & -50 & 48 \\ \text { Without performance covariate } & 3.00 & -36 & -52 & 48\end{array}$

(B) Greater activation in literates compared to illiterates in pseudowords versus words

Right frontal operculum/anterior insula region, BA 49*/45*/ $14^{*}$

$\begin{array}{lllll}\text { With performance covariate } & 2.70 & 20 & 22 & 32 \\ \text { Without performance covariate } & 2.78 & 22 & 22 & 28\end{array}$

Left anterior cingulate region, BA 24

$\begin{array}{lllll}\text { With performance covariate } & 3.05 & -14 & 28 & 16 \\ \text { Without performance covariate } & 3.59 & -16 & 26 & 12\end{array}$

\section{Left putamen/pallidum}

With performance covariate

$\begin{array}{llll}2.70 & -24 & 0 & -4\end{array}$

$\begin{array}{lllll}\text { Without performance covariate } & 3.20 & -20 & 0 & -4\end{array}$

Anterior thalamus/bypothalamus

$\begin{array}{lllll}\text { With performance covariate } & 3.03 & 2 & -8 & 0 \\ \text { Without performance covariate } & 3.04 & 0 & -6 & 0\end{array}$

Pons

$\begin{array}{lllll}\text { Without performance covariate } & 2.69 & -2 & -34 & -16\end{array}$

Medial cerebellum

$\begin{array}{llllll}\text { With performance covariate } & 2.67 & -10 & -70 & -16\end{array}$

$\begin{array}{lllll}\text { Without performance covariate } & 2.35 & -4 & -40 & -20\end{array}$
$2 \%$ of the errors in the literate and $11 \%$ of the errors in the illiterate group). The fact that the subjects repeated pseudowords (albeit sometimes incorrectly) makes it less likely that the differences in activation pattern is related to performance differences as such. In support of this there were no or only weak correlations between performance and regional cerebral blood flow in either group or condition using the local $Z$ maximum test statistic (overall $p \geq .2$ ). In addition, including the performance as a confounding covariate in the general linear model, the patterns of activations were similar. In particular, the differences between the literate and illiterate group were generally independent of whether the performance covariate was included in the analysis or not (Table 1).

\section{Functional Organization of Verbal Repetition and SEM}

SEM provides an opportunity to explicitly test hypotheses relating to functional-anatomical models subserving different cognitive functions in terms of which regions are involved and how they interact in a given network model. SEM has been used to investigate the covariance structure of functional neuroimaging data in a given cognitive state or during a specific task (Buchel \& Friston, 1997; Buchel, Coull, \& Friston, 1999; Nyberg et al., 1996; McIntosh et al., 1994; Horwitz \& McIntosh, 1993). For example, SEM has been used to investigate the effective connectivity (Friston, 1994) in visual processing (McIntosh et al., 1994), in assessing the effects of pallidotomy in Parkinson patients (Grafton, Sutton, Couldwell, Lew, \& Waters, 1994), in working memory (McIntosh et al., 1996), episodic memory retrieval (Nyberg et al., 1996), and visual attention (Buchel \& Friston, 1997). The network approach characterizes the functional organization in terms of effective connections between regions in a specific functional-anatomical model. This model is used in conjunction with SEM to model the observed covariance structure between the different regions of interest included in the network model.

\section{Functional-Anatomical Network Model}

The regions included in the functional-anatomical network model were represented as spherical regions of interests (ROIs, see Table 2) in the Karolinska Computerized Brain Atlas of Greitz (Greitz, Bohm, Holte, \& Eriksson, 1991). The ROIs were chosen based on the neuropsychology of language literature (Kolb \& Whishaw, 1996; Caplan, 1992; Mesulam, 1990; Patterson \& Shewell, 1987), functional neuroimaging data (Price et al., 1996; Price et al., 1997; Démonet et al., 1992; Démonet, Wise, \& Frackowiak, 1993; Démonet et al., 1996; Frackowiak, 1994; Liotti, Gay, \& Fox, 1994; Petersen et al., 1989; Petersen \& Fiez, 1993; Wise et al., 1991; 
Table 2. The Spherical Regions of Interest Used in the Functional-Anatomical Network Model were Located with the Help of the Karolinska Computerized Brain Atlas of Greitz (Greitz et al., 1991)

\begin{tabular}{llc}
\hline \multicolumn{1}{c}{ Region of interest } & $\begin{array}{c}\text { Brodmann's } \\
\text { area }\end{array}$ & $\begin{array}{c}\text { Diameter } \\
(\mathrm{mm})\end{array}$ \\
\hline Primary auditory cortex, left & BA 41/42 & 12 \\
Wernicke's area, left & BA 22 & 12 \\
Angular/supramarginal gyrus, left & BA 39/40 & 16 \\
Posterior-mid insula, left & BA 13/14 & 8 \\
$\begin{array}{l}\text { Broca's area, left } \\
\text { Lentiform nucleus, left }\end{array}$ & BA 44 & 12 \\
Lateral cerebellum, right & & 12 \\
$\begin{array}{l}\text { Primary motor region } \\
\text { (mouth area), left }\end{array}$ & BA 4 & 12 \\
Anterior cingulate cortex, left & BA 24/32 & 12 \\
Prefrontal cortex, left & BA 45/46 & 12 \\
\hline
\end{tabular}

See also Figure 2.

for a review see Habib \& Demonet, 1996), lesion data (Basso, Lecours, Moraschini, \& Vanier, 1985; Damasio \& Damasio, 1980), and from the activations reported in Castro-Caldas et al. (1998) as well as other functional neuroimaging studies (Carter et al., 1998; Paulesu et al., 1993; Paulesu et al., 1996; Salmon et al., 1996; Vandenberghe, Price, Wise, Josephs, \& Frackowiak, 1996; Buckner et al., 1995; D'Esposito et al., 1995; Petrides et al., 1993; Petrides, 1995; Petrides et al., 1995).
The objective of constructing the functional-anatomical model for language processing during verbal repetition was to generate a simple network that could explain a sufficient part of the observed covariance, both in the literate and illiterate group during word as well as pseudoword repetition. At the same time, we required that the network model should be both theoretically and empirically plausible. The functionalanatomical network model used included several ROIs (Table 2, Figure 2) and interconnections (Figure 3). For more details on the construction of the functionalanatomical network model, see the Methods section.

The right hemisphere language representation is less well known compared to the left hemisphere organization of language, in particular in illiterate subjects. There are some indications that language processing in illiterate subjects may, under certain circumstances, recruit bilateral brain regions to a greater extent than literate subjects (Petersson et al., 1999c; Castro-Caldas et al., 1998). In addition, some brain lesion data have been interpreted to indicate that the functional architecture of language is more bilaterally organized in illiterate compared to literate subject (Lecours et al., 1987a; Lecours et al., 1987b; Wechsler, 1976; Cameron, Currier, \& Haerer, 1971). However, this issue is complex and there are other data indicating that this may not always be the case (Damásio, Castro-Caldas, Grosso, \& Ferro, 1976a; Damásio, Castro-Caldas, Grosso, \& Ferro, 1976b). Furthermore, it is unclear how the right and left hemispheric language networks interact. Taken together and for simplicity we decided to restrict our analysis to the left hemisphere. However, given the possibility that the bilateral language processing in the illiterate
Figure 2. The anatomical localization of the regions of interest displayed in the anatomical space of Greitz (Greitz et al., 1991). The numbers displayed on the atlas correspond to the Brodmann's areas. $S=$ primary $/$ secondary auditory cortex, $\mathrm{W}=$ Wernicke's area, $\mathrm{iPC}=$ inferior parietal (angular/supramarginal gyrus) cortex, $\mathrm{pI}=$ posterior-mid insula, $\mathrm{B}=$ Broca's area, $\mathrm{M}=$ primary motor region of the mouth and larynx, $\mathrm{Cdx}=$ right lateral cerebellum, ACC $=$ anterior cingulate cortex, and $\mathrm{PFC}=$ middle-inferior prefrontal cortex. The location of the lentiform nucleus is not shown.

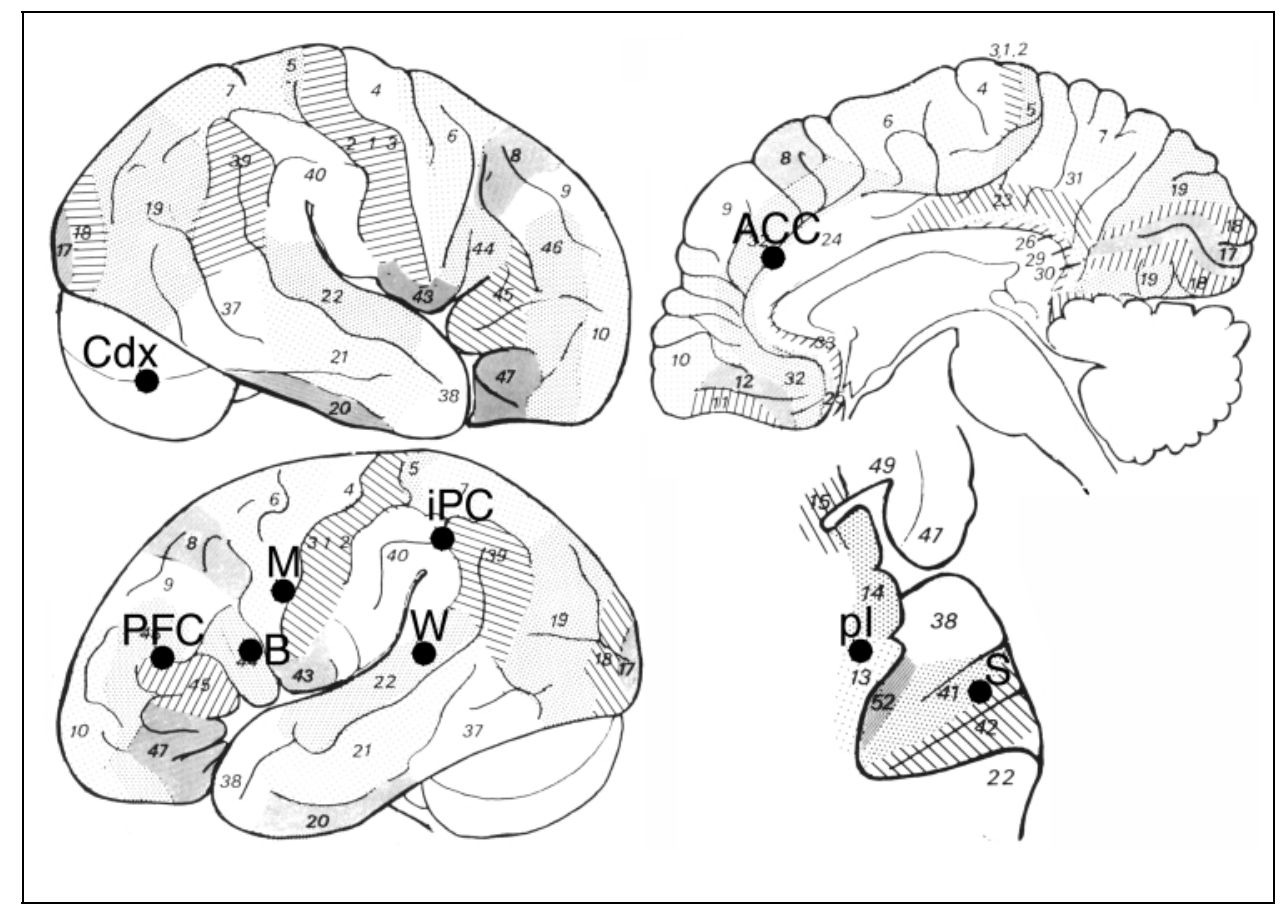


Figure 3. The connectivity of the functional-anatomical network model for language processing with the sub-networks outlined; the auditory input, the phonological loop, the articulatory motor subnetwork, the attention subnetwork, the central executive subnetwork. See text for details.

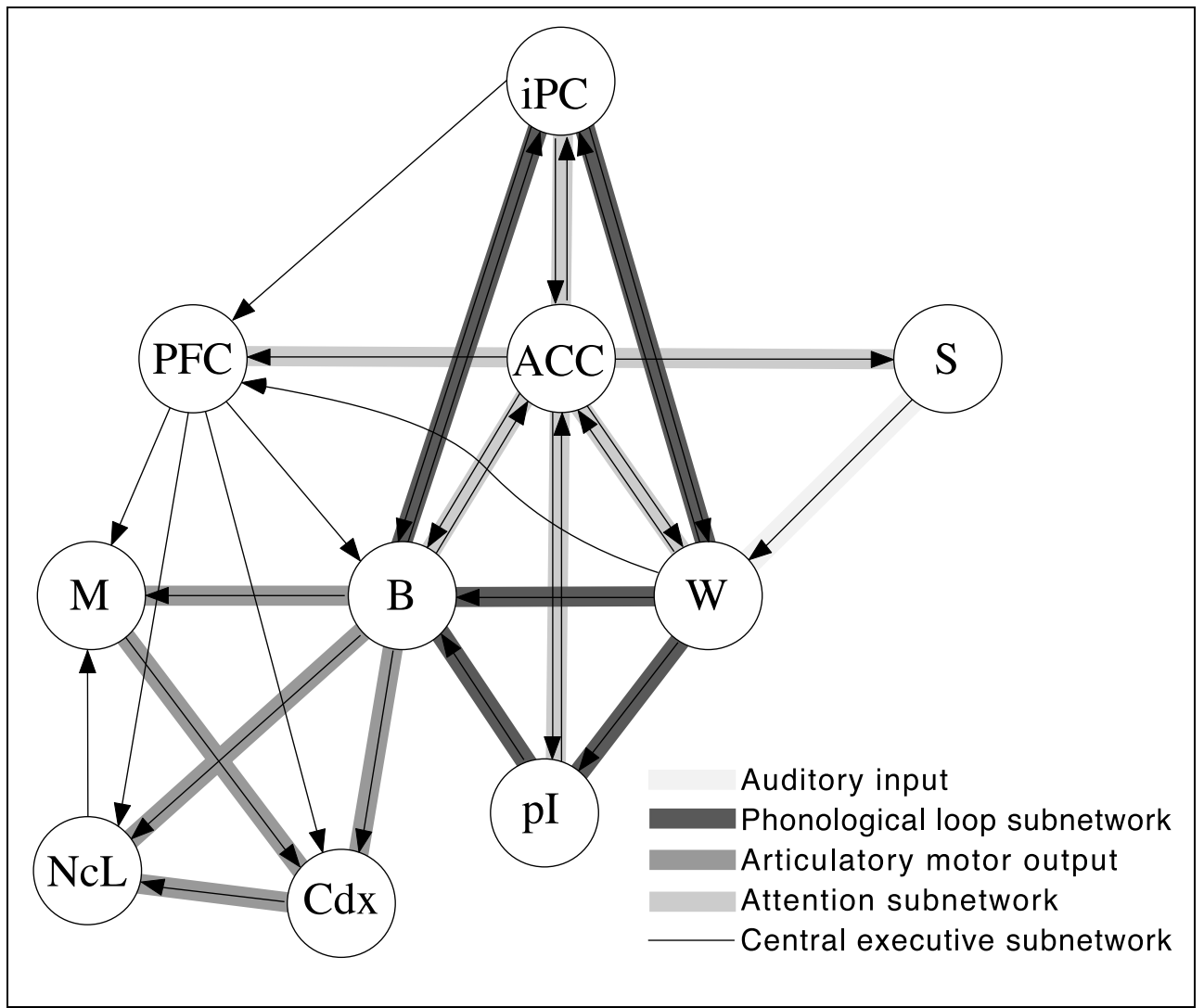

and literate subjects differ, it is not inconceivable that the inclusion of a right hemispheric network would accentuate the differences between the two literacy groups.

In the following, $\rightarrow$ indicates unidirectional connections while $\Longleftrightarrow$ indicates bidirectional or recurrent connections, that is, a feedforward and feedback connection, which are allowed to differ in connection weights. The network model (cf. Figure 3) includes a simplification of the Wernicke-Geschwind model (e.g., Kolb \& Whishaw, 1996) represented by the Wernicke's area (W, posterior third of left superior temporal gyrus, BA 22) connected to Broca's area (B, posterior part of left inferior frontal gyrus BA $44, \mathrm{~W} \rightarrow \mathrm{B}$ ) with input from the left primary/secondary auditory cortex (S, BA 41/42, $\mathrm{S} \rightarrow \mathrm{W}$ ) and a simple motor output circuit (left lenticular nucleus, NcL, and left primary motor cortex for articulation (the mouth and larynx area) $\mathrm{M}, \mathrm{BA} 4 ; \mathrm{B} \rightarrow \mathrm{M}$, $\mathrm{B} \rightarrow \mathrm{NCL} \rightarrow \mathrm{M})$. This core was extended to include the anterior cingulate cortex (ACC) hypothesized to be related to focused attention, error detection and response competition/selection (Carter et al., 1998; Vogt, Finch, \& Olson, 1992; Pardo et al., 1990; Posner \& Petersen, 1990). The network model was also extended to include the phonological loop as described by Paulesu et al. (1993, 1996). This introduced the inferior parietal cortex (iPC, on the border between angular and supramarginal gyrus, BA 39/40) and the posterior- midinsula (pI, BA 13 on the border of BA 14). The connections of the phonological loop were generally recurrent $(\mathrm{W} \Longleftrightarrow \mathrm{iPC} \Longleftrightarrow \mathrm{B})$. Since the insula has been hypothesized to be a neural relay for automatic language processing the connections to and from the posterior-midinsula were feedforward $(\mathrm{W} \rightarrow \mathrm{pI} \rightarrow \mathrm{B})$. The interactions between the ACC and the phonological loop were represented by recurrent connections $(\mathrm{W} \Longleftrightarrow \mathrm{ACC} \Longleftrightarrow \mathrm{B}$ and $\mathrm{pI} \Longleftrightarrow \mathrm{ACC} \Longleftrightarrow \mathrm{iPC}$ ). In addition, the left middle-inferior dorsolateral prefrontal region (PFC, on the border between BA 45 and 46) suggested to subserve the central executive aspects of verbal working memory (D'Esposito et al., 1995; Petrides et al., 1993; Petrides, 1995; Petrides et al., 1995), was included with input from the ACC, the Wernicke's area, and the inferior parietal cortex $(\mathrm{ACC} \rightarrow \mathrm{PFC}, \mathrm{W} \rightarrow \mathrm{PFC}$, $\mathrm{iPC} \rightarrow \mathrm{PFC})$ and with outputs modulating the organization of the articulatory motor output $(\mathrm{PFC} \rightarrow \mathrm{B}, \mathrm{PFC} \rightarrow \mathrm{M}$, $\mathrm{PFC} \rightarrow \mathrm{NCL}, \mathrm{PFC} \rightarrow \mathrm{Cdx})$. Finally, the right lateral cerebellar region $(\mathrm{Cdx})$ was included since this region has been related to certain aspects of language processing (Vandenberghe et al., 1996; Buckner et al., 1995; Raichle, 1994; Raichle et al., 1994) with inputs from cortical motor regions $(\mathrm{PFC} \rightarrow \mathrm{Cdx}, \mathrm{B} \rightarrow \mathrm{Cdx}, \mathrm{M} \rightarrow \mathrm{Cdx} \rightarrow \mathrm{NcL}$; cf., Figure 3). For a general empirical review of PET studies of cognition see Cabeza and Nyberg (1997) and for a review of the cerebellar contribution to cognition see Schmahmann (1996). 


\section{RESULTS}

The goodness-of-fit of the language network indicated that the network models fitted the observed covariance structure reasonably well in both groups and conditions (overall the goodness-of-fit corresponded to $p \geq .14$ in all groups and states, see Appendix). We used a hierarchical approach (Table 3 and Table 4) to test for differences between states and groups. First we tested if the network interactions in both conditions and groups could be explained by the same model using a stacked analysis (cf. the Methods section); this was not the case $(p=.003)$. We then tested for differences either between groups in a given state or between states in a given group. There was no significant difference in the pattern of network interactions between word and pseudoword repetition in the literate group $(p=.10)$. Neither was there any significant difference between the literate and illiterate group repeating words $(p=.10)$. In contrast, there were significant differences in the network interactions between word and pseudoword repetition in the illiterate group $(p=.002)$, and consistently, there were significant differences between the literate and illiterate group repeating pseudowords $(p=.038)$.

In a second step, we characterized the differences between word and pseudoword repetition in the illiterate group (Table 4, Figure 4) as well as the differences between the literate and the illiterate group repeating pseudowords (Table 4, Figure 5). Specifically, we localized the observed differences within the different subnetworks as far as the sensitivity in this study allowed to (Figure 3), and only the connections showing relative differences greater than or equal to .15 (standardized units) in connection strength were further investigated.

The differences between word and pseudoword repetition in the illiterate group were broadly related to attentional modulation (i.e., ACC connections, $p=.024$ ),

Table 3. The Results from the Omnibus Stacked Model Comparisons Between the Different Literacy Groups and Tasks

\begin{tabular}{ll}
\hline \multicolumn{1}{c}{ Omnibus comparison } & p value \\
\hline $\begin{array}{l}\text { Literate group, word/pseudoword, } \\
\text { illiterate, word/pseudoword repetition }\end{array}$ & .003 \\
$\begin{array}{l}\text { Literate group, } \\
\text { word versus pseudoword repetition }\end{array}$ & $\mathrm{ns}(.10)$ \\
$\begin{array}{l}\text { Illiterate group, } \\
\text { word versus pseudoword repetition }\end{array}$ & .002 \\
$\begin{array}{l}\text { Word repetition, } \\
\text { literate versus illiterate group }\end{array}$ & $\mathrm{ns}(.10)$ \\
Pseudoword repetition, \\
literate versus illiterate group
\end{tabular}

ns $=$ nonsignificant.
Table 4. The Results from the Sub-Network Stacked Comparisons

Omnibus subnetwork comparison p value
Illiterate group, word versus pseudoword repetition

$\begin{array}{lc}\text { Attention subnetwork } & .024 \\ \text { Central executive subnetwork } & .047 \\ \text { Phonological loop } & \mathrm{ns}(.10) \\ \text { Articulatory motor output } & .052\end{array}$

Pseudoword repetition, literate versus illiterate group

Attention subnetwork

.034

Central executive subnetwork

.045

Phonological loop

.036

Articulatory motor output

.085

For more detailed results see the Results section. Only connections showing differences $\geq .15$ in standardized units were investigated, ns $=$ nonsignificant.

executive aspects of processing (i.e., PFC connections, $p=.047)$, and the motor output circuit $(p=.052)$, while the differences relating to the phonological loop were nonsignificant $(p=.103)$. More specifically, the differences related to attentional modulation could be localized to the interaction between the ACC and the inferior parietal cortex (ACC $\Longleftrightarrow \mathrm{iPC}, p=.043$ ) as well as the posterior-midinsula ( $\mathrm{ACC} \Longleftrightarrow \mathrm{pI}, p=.044$ ). In addition, there were differences related to the prefrontal influence on the articulatory output of the language network and the motor subnetwork $(\mathrm{PFC} \rightarrow \mathrm{B}+\mathrm{PFC} \rightarrow$ $\mathrm{Cdx}+\mathrm{PFC} \rightarrow \mathrm{NcL}, p=.027$ ), finding its clearest expression in the connection $\mathrm{PFC} \rightarrow \mathrm{NcL}(p=.050)$. The differences in connections strengths of the articulatory output circuit mainly related to the influence of Broca's area on primary motor, lenticular nucleus and right lateral cerebellar regions $(p=.045)$

In repeating pseudowords, the literate and the illiterate group differed in attentional modulation of the auditory input and phonological loop of the language network $(p=.034)$. These differences related to the interactions between the ACC and the auditory input $(p=.069)$ as well as Broca's area and the posteriormidinsula $(p=.044)$. More specifically, it appeared that these differences related to the interactions between the ACC and the posterior-midinsula (AC$\mathrm{C} \Longleftrightarrow \mathrm{pI}, p=.049$ ) and the interaction between the ACC and Broca's area (ACC $\Longleftrightarrow \mathrm{B}, p=.074$ ). The interactions of the phonological loop differed between groups $(p=.036)$. These differences could be further localized to the interaction between Broca's area and the inferior parietal cortex $(p=.042)$. In addition, there were differences related to the posterior-midinsula $(\mathrm{W} \rightarrow \mathrm{pI} \rightarrow \mathrm{B}, p=.027)$, with contributions from 
Figure 4. The relative differences between word and pseudoword repetition in the illiterate group, that is, the difference between the corresponding connection strengths (word-pseudoword). Only differences $\geq .15$ in standardized units are shown. The omnibus comparison indicated that the difference were significant $(p=.002)$.

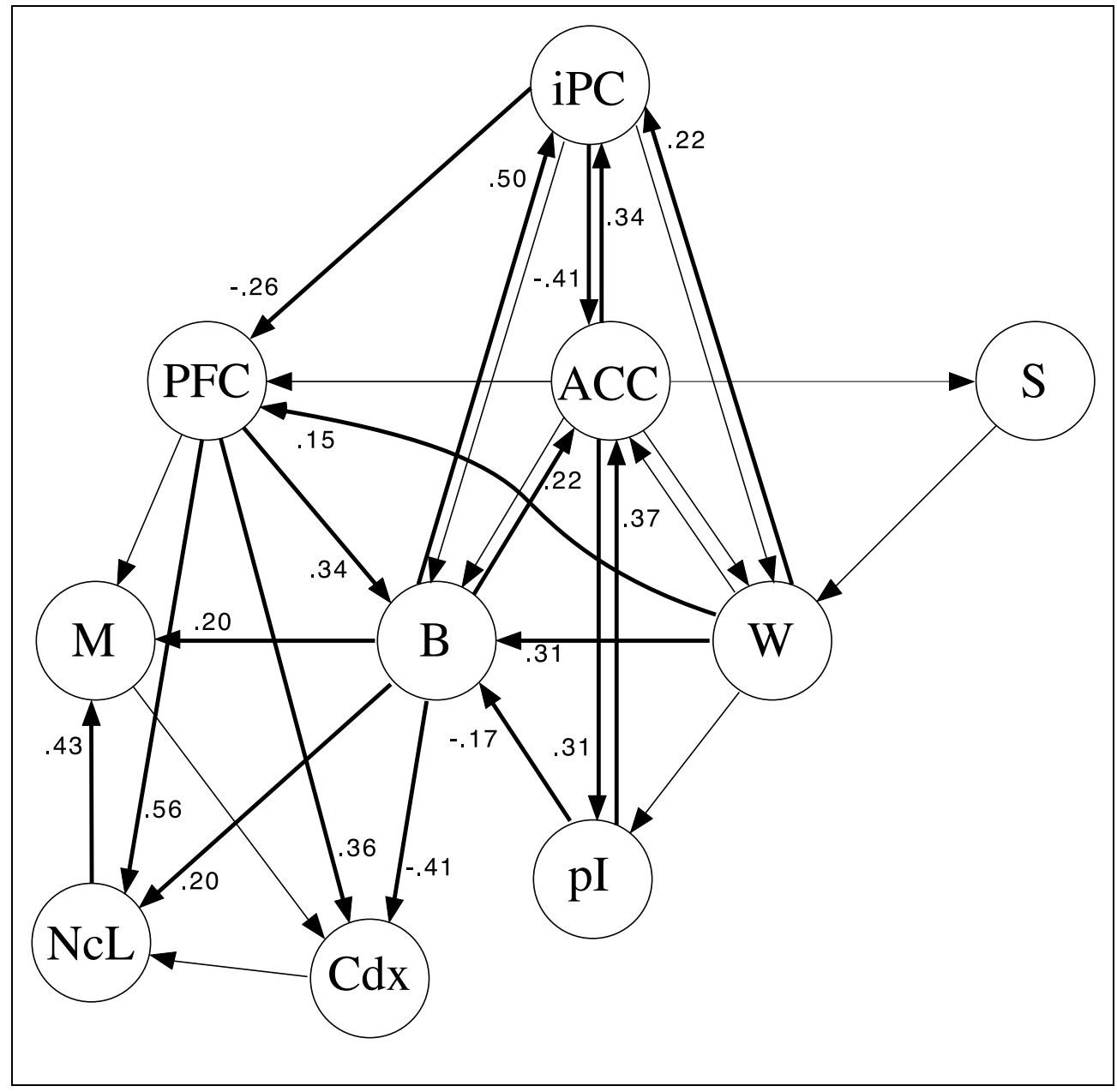

Wernicke's area (W $\rightarrow \mathrm{pI}, p=.057)$ and output to Broca's area $(\mathrm{pI} \rightarrow \mathrm{B}, p=.085)$. There were also differences related to the connections with the $\operatorname{PFC}(p=.045)$. In particular, the interactions between the inferior parietal and Broca's area via the $\mathrm{PFC}(\mathrm{iPC} \rightarrow \mathrm{PFC} \rightarrow \mathrm{B}, p=.042$; $\mathrm{iPC} \rightarrow \mathrm{PFC}, p=.064 ; \mathrm{PFC} \rightarrow \mathrm{B}, p=.064)$ differed between the literate and illiterate group. The differences related to the articulatory output circuit were statistically weaker $(\mathrm{Cdx} \rightarrow \mathrm{NcL} \rightarrow \mathrm{M}, p=.085)$.

\section{DISCUSSION}

Amongst others (Buchel \& Friston, 1997; McIntosh \& Gonzalez-Lima, 1994; McIntosh et al., 1996; Nyberg et al., 1996; Friston, 1994; Grafton et al., 1994), we have demonstrated the benefit of a network approach to the analysis of functional neuroimaging data, providing complementary information to the more common activation or general linear approach (Friston et al., 1995). The results of the network approach naturally have to be interpreted in the context of its limitations (cf. the Methods section).

The results of this study indicate that the network interactions were relatively similar during word and pseudoword repetition in literate subjects and also when literate and illiterate subjects repeated words. In contrast, there were significant differences in the network interactions when the illiterate subjects repeated words compared to pseudowords. Given the hypothesized functional role of the different regions included in the network model of language processing (cf. above), these differences were mainly related to those parts of the language network that may be viewed as general support and control systems, that is, central executive aspects of processing as well as attentional modulation. In addition, there were differences related to the motor circuit hypothesized to support the organization of articulatory output. There were no significant differences related to the phonological loop. The results also indicated significant differences between the literate and illiterate subjects when repeating pseudowords. These differences were related to the phonological loop, in particular the interactions between Broca's area and the inferior parietal region. There were also differences related to the posterior-midinsular bridge between Wernicke's and Broca's area. Additional differences related to attentional modulation of the auditory input, the Broca's and the posterior-midinsular regions as well as 
Figure 5. The relative differences during pseudoword repetition between the literate and the illiterate group, that is, the difference between the corresponding connection strengths (literate-illiterate). Only differences $\geq .15$ in standardized units are shown. The omnibus comparison indicated that the difference were significant $(p=.038)$.

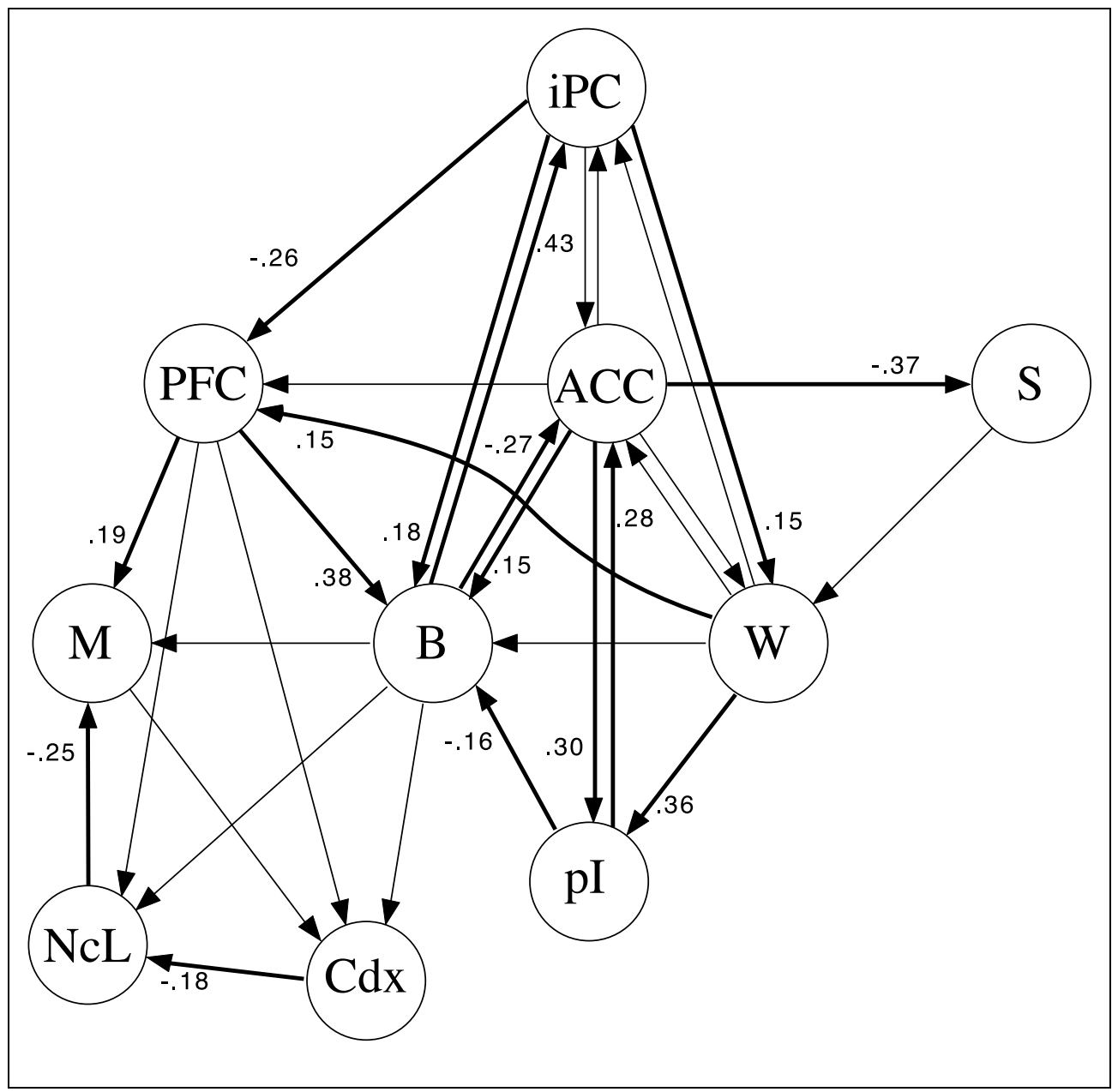

executive aspects of language processing and articulatory output.

The absence of significant difference between word and pseudoword repetition in the literate group indicates that the network interactions are relatively similar in word and pseudoword repetition. This can be interpreted to indicate that the literates automatically recruit a phonological processing network with sufficient competence for sublexical processing and segmentation during simple immediate verbal repetition, whether words or pseudowords, while this is not the case for the illiterate group. Especially since the network interactions differed significantly between word and pseudoword repetition in the illiterate group, this indicates that the illiterate subjects process words and pseudowords differently during verbal repetition. Consistently, the network interactions were significantly different when the literate and illiterate group repeated pseudowords, lending support to the interpretation that the illiterate subjects process pseudowords qualitatively differently compared to literate subjects.

Behavioral data indicate that illiterates are not fully competent in explicit manipulation of sublexical phonological structures (Castro-Caldas et al., 1998; Reis \&
Castro-Caldas, 1997; Morais et al., 1979; Morais, 1993). Pseudowords cannot be repeated exclusively using a lexico-semantic processing system or the type of (implicit) phonological system recruited by illiterate subjects. Instead, this seems to require an organization of the phonological system found in literate subjects. We have previously suggested that when literate subjects repeat pseudowords, they engage attentional/awareness components of phonological processing, which illiterate subjects fail to engage (Castro-Caldas et al., 1998). The production of motor sequences based on new phonological sequences not previously learned, as in pseudoword repetition, may depend on these aspects of phonological processing. This indicates that phonological attention/awareness are necessary for the de novo sequential arrangement of verbal output. In short, the present results in conjunction with previous data suggest that learning an alphabetic visual representation of language entails the development of new auditoryverbal processing capacities. Such acquired capacities may explain the differences in interaction pattern observed in the illiterate subjects that was not observed in literate subjects. In particular, the differences in the network interactions between groups when repeating 
pseudowords were broadly related to general support and control (i.e., attentional and central executive aspects of language processing) as well as the phonological loop and the organization of articulatory motor output.

Given our previous hypothesis and the suggested importance of inferior parietal, Wernicke's, Broca's, and insular regions subserving different aspects of phonological processing (Price et al., 1997; Démonet et al., 1996; Paulesu et al., 1996), one might expect differences in the connection strengths between the two literacy groups repeating pseudowords, reflecting the interactions within the phonological loop and between the phonological loop and the other subnetworks, that is, attentional mechanisms and executive or control aspects of verbal working memory. The phonological loop subnetwork was based on anatomical (Mesulam \& Mufson, 1985; Mesulam, 1990) and functional neuroimaging data (Salmon et al., 1996; Paulesu et al., 1993; Paulesu et al., 1995; Raichle, 1994; Raichle et al., 1994). This model of the phonological loop includes Wernicke's area (supporting input phonology), Broca's area (supporting output phonology), inferior parietal lobe (supporting the phonological store) and the posterior-midinsula, hypothesized to provide a "bridge" between Wernicke's and Broca's area (Raichle et al., 1994; Mesulam \& Mufson, 1985). In addition, based on functional neuroimaging data indicating that dyslectic subjects manifest phonological processing disturbances that parallels the inability to coordinate the interactions between the different regions of the phonological loop, it has been suggested that the (anterior) insula serve as a "bridge" between the inferior parietal region and Broca's area (Paulesu et al., 1996). In our previous report (CastroCaldas et al., 1998), the anterior insular and frontal opercular activations were observed in the literate group during pseudoword repetition (compared to word repetition), but not in the illiterate group. The lack of insular activation in the illiterate group may indicate the absence of an efficient link between the different components of phonological processing subserved by Wernicke's, Broca's, and inferior parietal regions. This is consistent with the interpretation of the insular role suggested by Paulesu et al. (1996). Furthermore, Raichle et al. (1994) have suggested that the (posterior) insula subserve more automatic aspects of language processing. In this context, it should be pointed out that there are widespread intrainsular connections that strongly interconnect the various sectors of the insular regions (Mesulam \& Mufson, 1985). Along the lines of Raichle (1994), Paulesu et al. (1993), and Paulesu et al. (1996), the results of the present network analysis indicate that illiterate subjects are not able to coordinate the interactions between the different regions of the phonological loop as literate subjects do during verbal repetition (see below). As previously noted, these differences were particularly related to the interactions between Broca's area and the inferior parietal region as well as the posterior-midinsular bridge between Wernicke's and Broca's area.

The ACC have been related to focused attention, error detection and response competition/selection (Carter et al., 1998; Vogt et al., 1992; Pardo et al., 1990; Posner \& Petersen, 1990), while the central executive aspects of verbal working memory have been related to the middle-inferior prefrontal region (BA 45/46) (D'Esposito et al., 1995; Petrides et al., 1993; Petrides, 1995; Petrides et al., 1995). The level of attentional processing, as indicated by the level of ACC activation, was greater in pseudoword compared to word repetition in the literate group (Castro-Caldas et al., 1998). This may reflect a greater need for attentional control (Carter et al., 1998; Cohen, Dunbar, \& McClelland, 1990; Cohen, ServanSchreiber, \& McClelland, 1992) to achieve a more effective phonological analysis during pseudoword repetition compared to word repetition. However, the absence of significant differences in the literate group between word and pseudoword repetition, both at the network level and at the behavioral level, indicate that the pattern of network interactions related to attentional modulation or executive control was qualitatively similar in both tasks. In contrast, the lack of significant increase of ACC activity in pseudoword compared to word repetition in the illiterate subjects may be related to the lack of explicit sublexical phonological awareness (Castro-Caldas et al., 1998). In addition, the pattern of network interactions related to attentional processing was different both in word compared to pseudoword repetition in the illiterate subjects as well as between the literate and illiterate group during pseudoword repetition. The differences between word and pseudoword repetition in illiterate subjects were mainly related to the interactions $\mathrm{ACC} \Longleftrightarrow \mathrm{iPC}$ and $\mathrm{ACC} \Longleftrightarrow \mathrm{pI}$. In addition to these findings, group differences during pseudoword repetition were also related to the interaction between the ACC and Broca's area as well as attentional modulation of the auditory input regions. This is consistent with the suggestions that the ACC subserve aspects of error detection and on-line monitoring of behavior (Carter et al., 1998). Interestingly, the difference in pseudoword repetition related to the interaction $\mathrm{ACC} \Longleftrightarrow$ pI represented decreases in connection strengths (both in literates vs. illiterates and in word vs. pseudoword repetition in the illiterate group), possibly reflecting the need to inhibit automatic language processing relayed via the insula (Raichle, 1994; Raichle et al., 1994; Mesulam \& Mufson, 1985). At the same time, there was a corresponding increase in connection strengths between the ACC and the inferior parietal and Broca's region, possibly reflecting a compensatory mechanism.

In the illiterate group, the differences in the interaction pattern related to the prefrontal region (word vs. pseudoword repetition) were mainly focused to the connections modulating the articulatory motor circuit. 
Differences were also related to the articulatory motor output circuit interactions themselves. This was also the case during pseudoword repetition in the literate versus illiterate comparison, indicating that the need to recruit executive aspects of verbal working memory to modulate and control the organization of articulatory output may differ between the literacy groups during pseudoword and also between word and pseudoword repetition in illiterate subjects. In addition, the organization of articulatory output itself may differ, requiring different compensatory processing when literate and illiterate subjects repeat pseudowords and when words and pseudowords are repeated by illiterate subjects.

In summary, a system for phonological processing and verbal repetition modulated by orthographic knowledge is available to literate subjects, including capacities needed for more demanding phonological tasks, e.g., successful pseudoword repetition. In contrast, illiterate subjects seem not to have such a formatted system for phonological processing. The results of the present network analysis are consistent with our hypothesis that the language networks in literate and illiterate subjects subserve qualitatively different parallel distributed and interactive processing reflecting the modulatory influence of having once received formal education and acquired the skills of reading and writing. The results are also consistent with our previous suggestion that these differences are related to attentional modulation, phonological processing, and the organization of articulatory output (Castro-Caldas et al., 1998; Petersson et al., 1998; Reis \& Castro-Caldas, 1997). However, it should be pointed out that the results of this study do not exclude the possibility that there are differences in network interactions between the two tasks in the literate group as well as between the literate and illiterate group repeating words. Since, given the network model, it is possible that the present results indicate that the magnitude of possible differences was not large enough, in relation to the observed variability, to be significant. The statistical power of the network approach to functional neuroimaging data is generally unknown (for a further discussion of the limitations of the network approach see the Methods section). In addition, the absence of significant differences between word and pseudoword repetition in literates may be related to the suggestion that the network model used captures more of the phonological rather than the semantic aspects of language processing.

\section{Conclusions}

Previous behavioral and functional neuroimaging data indicate that certain aspects of explicit phonological processing may not be acquired spontaneously, but are modulated by learning an alphabetic written language, that is, learning to read and write. It appears that learning an alphabetic written language modifies the auditory-verbal (spoken) language processing competence in a nontrivial way. Based on behavioral and functional neuroimaging data, we have suggested that spoken and written language interact not only during certain language tasks, but that learning and developing alphabetic written language capacities significantly modulates the spoken language system. Specifically, the acquisition of orthographic knowledge has a modulatory influence on sublexical phonological processing. This may result in a language network with different parallel interactive processing characteristics in literate and illiterate subjects. Specifically, the pattern of interactions in the language-processing network may differ between literate and illiterate subjects. In order to investigate this hypothesis, we analyzed the observed covariance structure in a PET data set from a simple auditory-verbal repetition paradigm (immediate repetition of words and pseudowords) in literate and illiterate subjects, from the same socio-cultural background in a fishermen community in southern Portugal, with a network approach based on SEM.

Based on a simple network model for language processing, the results of the present network analysis indicate that the network interactions during word and pseudoword repetition in the illiterate group differ, while there were no significant differences in the literate group. The differences between the two tasks in the illiterate group may reflect differences in attentional modulation of the language network, executive aspects of verbal working memory and the articulatory organization of verbal output. There were no significant differences between the literate and illiterate group during word repetition. In contrast, the network interactions differed between the literate and illiterate group during pseudoword repetition. In addition to differences similar to those observed in the illiterate group between word and pseudoword repetition, there were differences related to the interactions of the phonological loop. In particular, these differences between the two literacy groups related to the interaction between Broca's area and the inferior parietal cortex as well as the posteriormidinsula bridge between Wernicke's and Broca's area.

The results of this network analysis are consistent with our previously presented results and support the hypothesis that learning to read and write during childhood influences the functional architecture of the adult human brain. In particular, the basic auditory-verbal language network in the human brain is modified as a consequence of acquiring orthographic language skills.

\section{METHODS}

A detailed account of the PET study, the selection and experimental procedures has been published in CastroCaldas et al. (1998). In brief, subjects were classified as illiterate when they, for social reasons, had never entered school and had no knowledge of reading or 
writing. Twelve right-handed women (six literate and six illiterate subjects) from similar socio-cultural background in a homogeneous fishermen community in southern Portugal were included in the study. Literate and illiterate subjects were selected if they performed in the normal range $( \pm 1 S D$, norms according to age and literacy group) on all subtasks of a test-battery adapted for this population (Garcia \& Guerreiro, 1983). Previous diseases potentially involving the brain were ruled out by clinical assessment, previous clinical information provided by the local doctor and diagnostic MRI scans. The literate women had received 4 years of schooling and performed normally on reading comprehension and writing tests. Six lists of 20 high frequency three-syllable words were constructed based on frequency of use in common Portuguese spoken language (Nascimento, Rivenc, \& Cruz, 1987). Six lists of pseudowords were constructed based on the real words by changing the consonants and maintaining the vowels as well as the word length. The subjects were instructed to repeat words or pseudowords and to avoid any other type of speech production.

\section{PET Scanning and Data Preprocessing}

Repeated measurements of regional cerebral blood flow (rCBF, 6 word +6 pseudoword repetition tasks/ subject) were made with an ECAT Exact HR PET scanner in the 3-D acquisition mode (Wienhard et al., 1994) and bolus injections of $\left[{ }^{15} \mathrm{O}\right]$ butanol (Berridge, Cassidy, \& Terris, 1990). The PET images were realigned, spatially normalized and transformed into a common stereotactic anatomical space (Talairach \& Tournoux, 1988), 3-D isotropic Gaussian filtered and proportionally scaled to account for global confounders. In order to minimize the confounding contribution of filter-dependent spatial autocorrelation to the covariance of closely located regions of interest, a filter of $10 \mathrm{~mm}$ full width at half maximum (FWHM) was used (McIntosh et al., 1994). Adjusted data were generated using the SPM96 software (Wellcome Department of Cognitive Neurology, London, [Friston et al., 1995], see also http://www.fil.ion.bpmf.ac.uk/) removing subject effects modeled as block-confounders in the general linear model. The adjusted data were then transformed into the anatomical space of the Karolinska Computerized Brain Atlas of Greitz (Greitz et al., 1991).

\section{SEM and Data Analysis}

For adequate modeling it is required that the variations in the activity of the regions of interest (ROIs) are representative of respective functional region. For each scan and for each ROI, the activity was averaged across the voxels of the ROI, generating the ROI data. The covariance matrix of the ROI data was computed across subjects and repetitions $(6$ subjects $\times 6$ repetitions, i.e.,
36 observations) for each group and condition (literate/ illiterate, word/pseudoword), giving in total four covariance matrices. Correlation matrices were also computed and checked for high correlations, but none were detected, indicating that the amount of filtering was not too large in relation to the distance between the ROIs.

In general, SEM uses a linear system of equations to describe the interrelations of activities between the regions of the functional-anatomical model (McIntosh \& Gonzalez-Lima, 1994). SEM models are parameterized by the connection strengths (path coefficients or connection weights), the residuals, and the variances/covariances among and between these parameters (McIntosh \& Gonzalez-Lima, 1994; Bollen, 1989; Hayduk, 1987). Restrictions on these parameters in terms of constraints (e.g., fixed values, symmetry or more complex constraints) may be specified. In the models considered in this study, the residuals were fixed and the covariances between residuals were set to zero (McIntosh \& Gonzalez-Lima, 1994). The residuals of network components with more than one input were fixed to $66 \%$ while the residuals of components with only one input were fixed to $100 \%$ of the corresponding observed variance. Fixing residual parameters is to some extent arbitrary and the residuals may generally be thought of as the combined influences of regions not explicitly modeled and the influence of a brain region upon itself as well as measurement errors (McIntosh \& Gonzalez-Lima, 1994). In our case, the choice of values represents the hypothesis that the network model is a significant simplification of language processing, primarily taking into account phonological processing, and that the model is only expected to explain parts of the observed covariance structure. The standardized solutions, that is, the matrix of connection strength for each group and state, are reported in the Appendix. The connection strengths were estimated with an iterative maximum likelihood optimization process, using the LISREL software (version 7, Scientific Software, Mooresville, IN) for SEM modeling (Jöreskog \& Sörbom, 1989). The optimization process may informally be viewed as a procedure that recreates the observed covariance between regions as close as possible by finding the optimal values of the connection strengths. In LISREL, starting values are estimated using instrumental variables and a two-stage least square approach. The resulting estimates are statistically consistent, and with reasonably good fitting models, the initial estimates are close to the (iterative) maximum likelihood estimate (Jöreskog \& Sörbom, 1989).

Different network models were specified and connections strengths were estimated minimizing the maximum-likelihood norm between the empirically observed covariance structure (covariance matrix) and the covariance structure of the model network using least square estimates as initial values. For each model, the optimization process yields estimated connection strengths, goodness-of-fit estimates and modification 
indices indicating which connections may be introduced or freed to enhance the goodness-of-fit. The goodnessof-fit index used is the maximum-likelihood distance between implied and observed covariance structure. In the context of multivariate normally distributed variables, the goodness-of-fit index is $\chi^{2}$ distributed with $(q / 2)(q+1)-P$ degrees of freedom, where $P$ is the number of free parameters and $q$ is the number of observed variables (Bollen, 1989). The goodness-of-fit index can be translated into a $p$ value that indicates how well the model can explain or represent the observed covariance structure. Given that the model is correct, the $p$ value represents the probability of making an error when rejecting the null-hypothesis that the observed data could have been generated by the underlying model. This implies that a nonsignificant $p$ value $(>.05)$ is desirable indicating that a sufficient part of the observed covariance structure can be explained by the network model. Modification indices indicate ways that a given network model may be modified to increase the goodness-of-fit or the amount of observed covariances that can be explained (McIntosh \& Gonzalez-Lima, 1994; Bollen, 1989; Hayduk, 1987). The modification indices are of particular interest when the modifications suggested are consistent with theoretical or empirical considerations relating to the cognitive processes being modeled or known anatomical pathways. In this way, modification indices can be used to guide the model selection process (McIntosh \& Gonzalez-Lima, 1994). In the present study, there was a reasonable correspondence between good-fitting and theoretically plausible models in the sense that models with random connections often resulted in a marked drop in goodness-of-fit.

The described network approach, using SEM, generates quantitative estimates of the connection strengths between regions. The pattern of connection strengths can be compared between groups or conditions and using a stacked models analysis (McIntosh \& Gonzalez-Lima, 1994; Bollen, 1989; Hayduk, 1987). In a stacked analysis the connections strengths are estimated under the constraint that the corresponding connections are equal across groups or states. In a stacked analysis, if the underlying assumptions are valid, then the $p$ value reflects the goodness-of-fit of the hypothesis that the same set of network connections can explain the observed covariance structures across groups or states. Expressed more informally, that the cognitive processing in different groups or different conditions is qualitatively and quantitatively similar, as reflected in the network interactions of the functional neuroimaging data. Stacked analyses may also be performed on subnetworks by letting the complementary part of the network be free while the connection strengths of the subnetwork of interest are constrained to be the same. In this way, using a stacked analysis, it can be tested if the pattern of network interactions is different between groups or states.
During the initial model selection stage we also tested, to some extent, the stability of the results in relation to parameters such as the amount of filtering, small variations in the locations of the ROIs, different initial values, and the effects of different goodness-of-fit. To test the dependence on the amount of filtering, the data were also analyzed when Gaussian filtered (isotropic) at $16 \mathrm{~mm}$ FWHM. This yielded similar results in terms of the magnitude of path-coefficients and significance levels in the preliminary network models during the initial model selection stage. The results also seemed reasonably stable when small changes in the locations of the ROIs were introduced. Different initial values gave the same results. To control for effects of different goodness-of-fit of the individual (group or condition) models when running stacked models, networks with comparable fit for all conditions and groups was also analyzed, yielding similar results.

\section{Some Assumptions and Limitations of the Network Approach}

The SEM network approach described here is an example of a covariance-based approach (Horwitz \& McIntosh, 1993; Horwitz, Soncrant, \& Haxby, 1992). The basic hypothesis of different covariance based approaches is that the intrinsic variability in the neural response, during a cognitive state or particular task, will emulate the relevant functional interactions or effective connectivity (Friston, 1994; Friston, 1995). It is assumed that these interactions and the underlying (dynamic) functional architecture are reflected in the observed covariance structure. Two major ways of estimating the covariances within a cognitive state have been described: across subjects (Horwitz, McIntosh, Haxby, \& Grady, 1995), over time/repetitions within subject (Buchel \& Friston, 1997) or both (Buchel et al., 1999). In this context, it should be noted that the sources of within-state interregional covariances are beyond experimental control.

\section{Covariance Sources}

Several sources of interregional covariances have been proposed (Horwitz et al., 1992) and the actual sources of the observed covariances are largely unknown. However, some of the proposed sources may give rise to spurious correlations that are necessarily confounded with correlations arising because of the effective connectivity or the functional architecture (e.g., adaptation, fatigue, attentional drift; cf. Horwitz et al., 1992 and Buchel \& Friston, 1997). Obvious potential confounders in the study of interregional covariances are global effects. Variability in any global signal will introduce correlations that most often are of no interest. It has been suggested that the problem of global effects may be discounted by using partial correlation coefficients or proportional scaling, both of which yield 
similar results (Horwitz \& Rapoport, 1988). It has been indicated that accounting for global effects with simple approaches such as ANCOVA, proportional scaling or the use of partial correlation coefficients can in some circumstances yield biased results by introducing spurious correlations (Ford, 1986). However, it has been argued that such correlations often are small and that their presence can, to some extent, be tested for (Horwitz \& Rapoport, 1988). In any case, the presence of spurious correlations will bias the results to greater or lesser extent, unless properly removed or accounted for. Another possible source of confounding, when the covariances are calculated across subjects, is related to partial volume effects. This may be particularly relevant for networks including bilateral homologous structures. Homologous right-left structures are often relatively symmetric in size, shape, and position. Partial volume effects may thus introduce correlations between corresponding right-left structures. In addition, when the covariances are estimated over subjects, it is necessary to assume that the subjects implement a sufficiently similar functional organization. In this case, speaking informally, the covariance structure may reflect an average common functional architecture. In PET studies the number of intrasubject observations is limited (restricted by radiation exposure) and the data is often pooled over subjects in order to increase sensitivity. With FMRI data, it is possible to study functional and effective connectivity in single subjects (Buchel \& Friston, 1997). A distinct advantage with several single-subject studies is that these provide information on the generalizability of the results and the results may also be used in a meta-analytic approach.

\section{Specific Limitations of Structural Equations Modeling}

The results of SEM analysis are potentially difficult to interpret for several reasons. For example, there is no guarantee that the connections modeled reflect direct effective connections; it is possible that they are mediated through areas or connections not included in the model. Similarly, observed changes in the weights between states or groups may reflect common input from regions not modeled. This touches on the problem of model selection, that is, the general problem of matching model and data complexity. In the case of SEM, model selection may be performed in a data-driven manner, guided by goodness-of-fit values, modification indices or using a hierarchical model building approach when subsets of weights are estimated recursively (McIntosh \& Gonzalez-Lima, 1994). The data-driven approach is vulnerable to over-fitting since sample specific characteristics may be modeled (e.g., noise and outliers). Investigating over-fitted models can limit the generalizability of results. Alternatively, model selection may be theory driven, running the risk of investigating incomplete models. Unless reasonable goodness-of-fit can be achieved with a given model in all states or groups investigated, the results of a stacked models comparison can be difficult to interpret. For example, using an underparameterized model to test differences between states or groups in a stacked analysis may yield results due to an ill-fitting model in one of the states or groups. The effect of using under-parameterized models has been investigated to some extent in a simple network model (McIntosh \& Gonzalez-Lima, 1994). This simulation study indicate that the results from analyzing moderately reduced models are fairly stable and that the modification indices can to some extent provide indications of omissions of connections or regions in the chosen model. It should also be noted that the maximum likelihood estimation of the SEM approach assumes that a global optimum has been reached. The standard implementation in LISREL uses instrumental variables and a two-stage least square approach in combination with the Davidon-Fletcher-Power algorithm and line search to find a (local) optimum of the objective function, which in practice often is close to the global optimum (cf. Bollen, 1989; Jöreskog \& Sörbom, 1986). In general, the cost (or objective) function to be optimized is a complicated nonlinear function of the model parameters and often an explicit global optimum solution is not known (Bollen, 1989). In addition, it is possible that the objective function has several local optima. In such a case, there is no guarantee that the global optimum will be reached with deterministic gradient descent algorithms or nonexhaustive search procedures. Alternatively, a simulated annealing approach to optimization can be used (Kirkpatrick, Gelatt, \& Vecchi, 1983; Kirkpatrick \& Sorkin, 1995). These and other issues are discussed further in Petersson et al., 1999a and Petersson et al., 1999b.

\section{Appendix}

The connection strength matrices of the literate and illiterate group in the word and pseudoword repetition tasks.

Literate, word repetition:

Goodness-of-fit corresponding to $p=.16$

$\begin{array}{lrrrrrrrrrr} & \text { ACC } & \text { B } & \text { Cdx } & \text { iPC } & \text { PFC } & \text { M } & \text { NcL } & \text { pI } & \text { S } & \text { W } \\ \text { ACC } & .00 & -.24 & .00 & -.13 & .00 & .00 & .00 & .11 & .00 & .09 \\ \text { B } & -.18 & .00 & .00 & -.05 & .09 & .00 & .00 & .23 & .00 & .26 \\ \text { Cdx } & .00 & .26 & .00 & .00 & .06 & -.29 & .00 & .00 & .00 & .00 \\ \text { iPC } & -.19 & -.19 & .00 & .00 & .00 & .00 & .00 & .00 & .00 & .19 \\ \text { PFC } & -.01 & .00 & .00 & -.14 & .00 & .00 & .00 & .00 & .00 & .37 \\ \mathrm{M} & .00 & .52 & .00 & .00 & -.07 & .00 & .01 & .00 & .00 & .00 \\ \mathrm{NCL} & .00 & -.02 & .00 & .00 & .39 & .00 & .00 & .00 & .00 & .00 \\ \mathrm{pI} & .12 & .00 & .00 & .00 & .00 & .00 & .00 & .00 & .00 & -.12 \\ \mathrm{~S} & .15 & .00 & .00 & .00 & .00 & .00 & .00 & .00 & .00 & .00 \\ \mathrm{~W} & -.06 & .00 & .00 & .09 & .00 & .00 & .00 & .00 & .53 & .00\end{array}$

Volume 12, Number 3 
Literate, pseudoword repetition:

Goodness-of-fit corresponding to $p=.14$

$\begin{array}{llllllllll}\text { ACC } & B & \text { Cdx } & \text { iPC } & \text { PFC } & \text { M } & \text { NCL } & \text { pI } & \text { S } & \text { W }\end{array}$

$\begin{array}{lrrrrrrrrrr}\mathrm{ACC} & .00 & .03 & .00 & .02 & .00 & .00 & .00 & .14 & .00 & .01 \\ \mathrm{~B} & .01 & .00 & .00 & .07 & .26 & .00 & .00 & .19 & .00 & .04 \\ \mathrm{Cdx} & .00 & .28 & .00 & .00 & -.07 & .04 & .00 & .00 & .00 & .00 \\ \mathrm{iPC} & .10 & .09 & .00 & .00 & .00 & .00 & .00 & .00 & .00 & -.15 \\ \mathrm{PFC} & .08 & .00 & .00 & -.34 & .00 & .00 & .00 & .00 & .00 & .13 \\ \mathrm{M} & .00 & .32 & .00 & .00 & .26 & .00 & -.08 & .00 & .00 & .00 \\ \mathrm{NCL} & .00 & -.03 & .12 & .00 & .30 & .00 & .00 & .00 & .00 & .00 \\ \mathrm{pI} & .11 & .00 & .00 & .00 & .00 & .00 & .00 & .00 & .00 & .31 \\ \mathrm{~S} & -.17 & .00 & .00 & .00 & .00 & .00 & .00 & .00 & .00 & .00 \\ \mathrm{~W} & .10 & .00 & .00 & -.03 & .00 & .00 & .00 & .00 & .32 & .00\end{array}$

Illiterate, word repetition:

Goodness-of-fit corresponding to $p=.22$

$\begin{array}{llllllllll}\text { ACC } & B & \text { Cdx } & \text { iPC } & \text { PFC } & M & \text { NCL } & \text { pI } & S & \text { W }\end{array}$

$\begin{array}{lrrrrrrrrrr}\mathrm{ACC} & .00 & .08 & .00 & -.25 & .00 & .00 & .00 & .23 & .00 & .05 \\ \mathrm{~B} & .26 & .00 & .00 & -.06 & .22 & .00 & .00 & .18 & .00 & .22 \\ \mathrm{Cdx} & 0.00 & -.15 & .00 & .00 & .34 & .15 & .00 & .00 & .00 & .00 \\ \mathrm{iPC} & -.15 & .16 & .00 & .00 & .00 & .00 & .00 & .00 & .00 & .18 \\ \mathrm{PFC}-.05 & .00 & .00 & -.36 & .00 & .00 & .00 & .00 & .00 & .33 \\ \mathrm{M} & .00 & .60 & .00 & .00 & .08 & .00 & .17 & .00 & .00 & .00 \\ \mathrm{NCL} & .00 & .09 & -.14 & .00 & -.12 & .00 & .00 & .00 & .00 & .00 \\ \mathrm{pI} & .20 & .00 & .00 & .00 & .00 & .00 & .00 & .00 & .00 & -.06 \\ \mathrm{~S} & .32 & .00 & .00 & .00 & .00 & .00 & .00 & .00 & .00 & .00 \\ \mathrm{~W} & -.06 & .00 & .00 & .19 & .00 & .00 & .00 & .00 & .33 & .00\end{array}$

Illiterate, pseudoword repetition:

Goodness-of-fit corresponding to $p=.18$

$\begin{array}{llllllllll}\text { ACC } & B & \text { Cdx } & \text { iPC } & \text { PFC } & \text { M } & \text { NCL } & \text { pI } & \text { S } & \text { W }\end{array}$

$\begin{array}{lrrrrrrrrrr}\text { ACC } & .00 & .30 & .00 & .16 & .00 & .00 & .00 & -.14 & .00 & .10 \\ \mathrm{~B} & .16 & .00 & .00 & -.11 & -.12 & .00 & .00 & .35 & .00 & -.09 \\ \mathrm{Cdx} & .00 & .26 & .00 & .00 & -.02 & -.32 & .00 & .00 & .00 & .00 \\ \mathrm{iPC} & .19 & -.34 & .00 & .00 & .00 & .00 & .00 & .00 & .00 & -.04 \\ \mathrm{PFC} & .01 & .00 & .00 & -.10 & .00 & .00 & .00 & .00 & .00 & .28 \\ \mathrm{M} & .00 & .40 & .00 & .00 & .07 & .00 & -.26 & .00 & .00 & .00 \\ \mathrm{NCL} & .00 & -.11 & -.06 & .00 & .44 & .00 & .00 & .00 & .00 & .00 \\ \mathrm{pI} & -.19 & .00 & .00 & .00 & .00 & .00 & .00 & .00 & .00 & -.06 \\ \mathrm{~S} & .20 & .00 & .00 & .00 & .00 & .00 & .00 & .00 & .00 & .00 \\ \mathrm{~W} & .04 & .00 & .00 & .11 & .00 & .00 & .00 & .00 & .33 & .00\end{array}$

\section{Acknowledgments}

This study is part of the EU Biomed 1 programme (BMHI CT941261) and was financed in part by grants from the Swedish Medical Research Council (8276, 12716), the Karolinska Institute, the Knut and Alice Wallenberg Foundation, the Swedish Bank Tercentenary Foundation and project STRIDE (no 352/92-JNICT). The authors also want to thank the volunteers for their participation, Dr Fransisco Reis who assisted in the recruitment of subjects, and the help of the Portuguese Embassy in Stockholm.

Reprint requests should be sent to Dr. Karl Magnus Petersson, Cognitive Neurophysiology R2-01, Department of Clinical Neuroscience, Karolinska Institute, Karolinska Hospital, 171 76 Stockholm, Sweden, email: karlmp@neuro.ks.se.

\section{REFERENCES}

Adrian, J. A. (1993). Habilidade metafonoligica en sujetos analfabetos y malos lectores. Boletin de Psicologia, 39, 7-19.

Aertsen, A. M. H., Gerstein, G. L., Habib, M. K., \& Palm, G. (1989). Dynamics of neuronal firing correlation: Modulation of "effective connectivity". Journal of Neurophysiology, 61, 900-917.

Aertsen, A. M. H., \& Preissl, H. (1991). Dynamics of activity and connectivity in physiological neuronal networks. In: H. G. Schuster (Ed.), Nonlinear Dynamics and Neuronal Networks (pp. 281-302), New York: VHC Publishers.

Amit, D. J. (1989). Modeling brain function: The world of attractor neural networks, Cambridge, UK: Cambridge Universiy Press.

Arbib, M. A. (Ed.) (1995). The handbook of brain theory and neural networks, Cambridge, MIT Press.

Baddeley, A. (1992). Working memory. Science, 255, 556-559.

Baddeley, A. (1997). Human memory: Theory and practice, Revised ed. Erlbaum.

Baddeley, A., Gathercole, S., \& Papagno, C. (1998). The phonological loop as a language learning device. Psychology Review, 105, 158-173.

Basso, A., Lecours, A. R., Moraschini, S., \& Vanier, M. (1985). Anatomo-clinical correlations of the aphasias as defined through computerized tomography: On exceptions. Brain and Language, 26, 201-229.

Berridge, M. S., Cassidy, E. H., \& Terris, A. H. (1990). A routine, automated synthesis of oxygen-15-labeled butanol for positron tomography. Journal of Nuclear Medicine, 31, 1727-1731.

Bollen, K. A. (1989). Structural equations with latent variables. New York: Wiley.

Buchel, C., Coull, J. T., \& Friston, K. J. (1999). The predictive value of changes in effective connectivity for human learning. Science, 283, 1538-1541.

Buchel, C., \& Friston, K. J. (1997). Modulation of connectivity in visual pathways by attention: Cortical interactions evaluated with structural equation modelling and fMRI. Cerebral Cortex, 7, 768-778.

Buckner, R. L., Petersen, S. E., Ojemann, J. G., Miezin, F. M., Squire, L. R., \& Raichle, M. E. (1995). Functional anatomical studies of explicit and implicit memory retrieval tasks. Journal of Neuroscience, 15, 12-29.

Cabeza, R., \& Nyberg, L. (1997). Imaging cognition: An empirical review of PET studies with normal subjects. Journal of Cognitive Neuroscience, 9, 1-26.

Cameron, R. F., Currier, R. D., \& Haerer, A. F. (1971). Aphasia and literacy. British Journal of Disorder Communication, 6 , 161-163. 
Caplan, D. (1992). Structure, processing and disorders, Cambridge: MIT Press.

Carter, C. S., Braver, T. S., Barch, D. M., Botvinick, M. M., Noll, D., \& Cohen, J. D. (1998). Anterior cingulate cortex, error detection, and the online monitoring of performance. Science, 280, 747-749.

Castro-Caldas, A., Miranda Cavaleiro, P., Carmo, I., Reis, A. Leote, F., Ribeiro, C., \& Ducla-Soares, E. (1999). Influence of learning to read and write on the morphology of the corpus callosum. European Journal of Neurology, $6,23-28$.

Castro-Caldas, A., Petersson, K. M., Reis, A., Stone-Elander, S., \& Ingvar, M. (1998). The illiterate brain: Learning to read and write during childhood influences the functional organization of the adult brain. Brain, 121, 1053-1063.

Castro-Caldas, A., Reis, A., \& Guerreiro, M. (1997). Neuropsychological aspects of illiteracy. Neuropsychological Rebabilitation, 7, 327-338.

Cohen, J. D., Dunbar, K., \& McClelland, J. L. (1990). On the control of automatic processes: A parallel distributed processing model of the Stroop effect. Psychological Review, 99, 45-77.

Cohen, J. D., Servan-Schreiber, D., \& McClelland, J. L. (1992). A parallel distributed processing approach to automaticity. American Journal of Psychology, 105, 239-269.

Costlett, H. B., Roeltgen, D. P., Rothi, L. G., \& Heilman, K. (1987). Transcortical sensory aphasia: Evidence for subtypes. Brain and Language, 32, 362-378.

Damásio, A. R., Castro-Caldas, A., Grosso, J. T., \& Ferro, J. M. (1976). Brain specialization for language does not depend on literacy. Archives of Neurology, 33, 300-301.

Damásio, A. R., Castro-Caldas, A., Grosso, J. T., \& Ferro, J. M. (1976). Letter to the Editor. Archives of Neurology, 33, 662

Damasio, H., \& Damasio, A. R. (1980). The anatomical basis of conduction aphasia. Brain, 103, 337-350.

Démonet, J.-F., Chollet, F., Ramsay, S., Cardebat, D., Nespoulous, J.-L., Wise, R., Rascol, A., \& Frackowiak, R. S. J. (1992). The anatomy of phonological and semantic processing in normal subjects. Brain, 117, 1753-1768.

Démonet, J.-F., Fiez, J. A., Paulesu, E., Petersen, S. E., \& Zatorre, R. J. (1996). PET Studies of phonological processing: A critical reply to Poeppel. Brain and Language, 55, 352-379.

Démonet, J.-F., Price, C., Wise, R., \& Frackowiak, R. S. J. (1994). A PET study of cognitive strategies in normal subjects during language tasks: Influence of phonetic ambiguity and sequence processing on phoneme monitoring. Brain, 117, 671-682.

Démonet, J.-F., Wise, R., \& Frackowiak, R. S. J. (1993). Language functions explored in normal subjects by positron emission tomography: A critical review. Human Brain Mapping, 1, 39-47.

D'Esposito, M., Detre, J. A., Alsop, D. C., Shin, R. K., Atlas, S., \& Grossman, M. (1995). The neural basis of the central executive system of working memory. Nature, 378, 279-281.

Felleman, D. J., \& Van Essen, D. C. (1991). Distributed hierarchical processing in the primate cerebral cortex. Cerebral Cortex 1, 1-47.

Fodor, J. A., \& Pylyshyn, Z. W. (1990). Connectionism and cognitive architecture: A critical analysis. Cognition, 28, $3-71$.

Ford, I. (1986). Confounded correlations: Statistical limitations in the analysis of interregional relationships of cerebral metabolic activity. Journal of Cerebral Blood Flow and Metabolism, 6, 385-388.

Frackowiak, R. S. J. (1994). Functional mapping of of verbal memory and language. TINS, 17, 109-115.

Friston, K. (1994). Functional and effective connectivity. Human Brain Mapping, 2, 56-78.
Friston, K., Holmes, A., Worsley, K., Poline, J.-B., Frith, C., \& Frackowiak, R. (1995). Statistical parametric maps in functional imaging: A general linear approach. Human Brain Mapping, 2, 189-210.

Friston, K. J. (1995). Commentary and opinion: II. Statistical parametric mapping - Ontology and current issues. Journal of Cerebral Blood Flow and Metabolism, 15, 361-370.

Friston, K. J., Frith, C. D., Liddle, P. F., \& Frackowiak, R. S. (1993). Functional connectivity: The principal-component analysis of large (PET) data sets. Journal of Cerebral Blood Flow and Metabolism, 13, 5-14.

Garcia, G., \& Guerreiro, M. (1983). Pseudo-dementia in illiteracy. 6th European meeting of the International Neuropsychological Society.

Gathercole, S. E., \& Baddeley, A. D. (1993). Working memory and language, Hove, UK: Erlbaum.

Gathercole, S. E., \& McCarthy, R. A. (1994). Memory tools for the researcher and clinician. Memory, 2, 97-101.

Gathercole, S. E., Willis, C. S., Baddeley, A. D., \& Emslie, H. (1994). The children's test of nonword repetition: A test of phonological working memory. Memory, 2, 103-127.

Glosser, G., Kohn, S. E., Friedman, R. B., Sands, L., \& Grugan, P. (1997). Repetition of single words and nonwords in Alzheimer's disease. Cortex, 3, 653-666.

Grafton, S. T., Sutton, J., Couldwell, W., Lew, M., \& Waters, C. (1994). Network analysis of motor system connectivity in Parkinson's disease: Modulation of thalamocortical interactions after pallidotomy. Human Brain Mapping, 2, 45-55.

Greitz, T., Bohm, C., Holte, S., \& Eriksson, L. (1991). A computerized brain atlas: Construction, anatomical content and some applications. Journal of Computer Assisted Tomography, 15, 26-38.

Habib, M., \& Démonet, J.-F. (1996). Cognitive neuroanatomy of language: The contribution of functional neuroimaging. Aphasiology, 10, 217-234.

Hayduk, L. A. (1987). Structural equation modeling with LISREL, Baltimore, MD: Johns Hopkins.

Herbster, A. N., Mintun, M. A., Nebes, R. D., \& Becker, J. T. (1997). Regional cerebral blood flow during word and nonword reading. Human Brain Mapping, 5, 84-92.

Horwitz, B., \& McIntosh, A. R. (1993). Network modeling and functional neuroimaging for mapping brain cognitive function. In: K. Uemura, N. A. Lassen, T. Jones \& I. Kanno (Eds.), Quantification of Brain Function, (pp. 589-596), Amsterdam, Netherlands: Elsevier.

Horwitz, B., McIntosh, A. R., Haxby, J. V., \& Grady, C. L. (1995). Network analysis of brain cognitive function using metabolic and blood flow data. Behavioural Brain Research, 66, 187-93.

Horwitz, B., \& Rapoport, S. I. (1988). Partial correlation coefficients approximate the real intrasubject correlation pattern in the analysis of interregional relations of cerebral metabolic activity. Journal of Nuclear Medicine, 29, 392-399.

Horwitz, B., Soncrant, J. V., \& Haxby, J. V. (1992). Covariance analysis of functional interactions in the brain using metabolic and blood flow data. In: F. Gonzalez-Lima, T. Finkenstaedt \& H. Scheich (Eds.), Advances in Metabolic Mapping Techniques for Brain Imaging of Behavioral and Learning Functions, (pp. 189-217). Dordrecht, Netherlands: Kluwer Academic Publishing.

Ingvar, M., \& Petersson, K. M. (2000), forth coming. Functional maps and brain networks. In: A. W. Toga \& J. C. Mazziotta (Eds.), Brain Mapping: The Systems, San Diego, CA: Academic Press.

Jöreskog, K., \& Sörbom, D. (1986). LISREL VI: Analysis of linear structural relationships by maximum likelibood and least square methods, Mooresville, IN: Scientific Software. 
Jöreskog, K., Sörbom, D., (1989). LISREL 7 user's reference guide, Mooresville, IN: Scientific Software.

Kirkpatrick, S., Gelatt, C. D., \& Vecchi, M. P. (1983). Optimization by simulated annealing. Science, 220, 671-680.

Kirkpatrick, S., \& Sorkin, G. B. (1995). Simulated annealing. In: M. A. Arbib (Ed.), The handbook of brain theory and neural networks, (pp. 876-879). Cambridge: MIT Press.

Koch, C., \& Davis, J. L. (1994). Large-scale neuronal theories of the brain, Cambridge: MIT Press.

Kolb, B., \& Whishaw, I. Q. (1996). Fundamentals of human neuropsychology, New York: W. H. Freeman and Company.

Lecours, A. R., Mehler, J., Parente, M. A., Aguiar, L. R., Silva, A., B., Caetano, M., Camarotti, H., Castro, M. J., Dehaut, F., Dumais, C., Gauthier, L., Gurd, J., Leitao, O., Maciel, J., Machado, S., Melaragno, R., Oliveira, L. M., Paciornik, J., Sanvito, W., Silva, E. S., Silifrandi, M., \& Torné, C. H. (1987a). Illiteracy and Brain Damage: 2. Manifestations of unilateral neglect in testing "auditory comprehension" with iconographic materials. Brain and Cognition, 6, 243-265.

Lecours, A. R., Mehler, J., Parente, M. A., Beltrami, M. C., Silva, A., B., Tolipan, L. C., Cary, L., Castro, M. J., Carrono, V., Chagastelles, L., Dehaut, F., Delgado, R., Evangelista, A., Fajgenbaum, S., Fontoura, C., Karmann, D. F., Gurd, J., Torné, C. H., Jakubovicz, R., Kac, R., Lefevre, B., Lima, B., Maciel, J., Mansur, L., Martinez, R., Nobrega, M. C., Osorio, Z., Paciornik, J., Papaterra, F., Penedo, M. A. J., Saboya, B., Scheuer, C., Silva, A. B., Spinardi, M., \& Teixeira, M. (1987b). Illiteracy and Brain Damage: 3. A contribution to the study of speech and language disorders in illiterates with unilateral brain damage (initial testing). Neuropsychologia, 26, 575-589.

Liotti, M., Gay, C. T., \& Fox, P. T. (1994). Functional imaging and language: Evidence from positron emission tomography. Journal of Clinical Neurophysiology, 11, 175-190.

Macdonald, C., \& Macdonald, G. (1995). Connectionism: Debates on Psychological Explanation, Oxford, UK: Blackwell Publishers.

Martin, N., \& Saffran, E. M. (1992). A computational account of deep dysphasia: Evidence from a single case study. Brain and Language, 43, 240-274.

McIntosh, A. R., \& Gonzalez-Lima, F. (1991). Structural modeling of functional neural pathways mapped with 2-deoxyglucose: Effects of acoustic startle habituation on the auditory system. Brain Research, 547, 295-302.

McIntosh, A. R., \& Gonzalez-Lima, F. (1994). Structural equation modeling and its application to network analysis in functional brain imaging. Human Brain Mapping, 2, 2-22.

McIntosh, A. R., Grady, C. L., Haxby, J. V., Ungerleider, L. G., \& Horwitz, B. (1996). Changes in limbic and prefrontal functional interactions in a working memory task for faces. Cerebral Cortex, 6, 571-584.

McIntosh, A. R., Grady, C. L., Ungerleider, L. G., Haxby, J. V., Rapoport, S. I., \& Horwitz, B. (1994). Network analysis of cortical visual pathways mapped with PET. Journal of Neuroscience, 14, 655-66.

Mesulam, M.-M., \& Mufson, E. J. (1985). The insula of Reil in man and monkey: Architectonics, connectivity, and function. In: A. Peters \& E. G. Jones (Eds.), Cerebral cortex, (pp. 179226). New York: Plenum.

Mesulam, M. M. (1990). Large-scale neurocognitive networks and distributed processing for attention, language, and memory. Annals of Neurology, 28, 597-613.

Mesulam, M. M. (1998). From sensation to cognition. Brain, 121, 1013-1052.

Morais, J. (1993). Reading disabilities: Diagnosis and component processes. In: R. M. Joshi \& C. K. Leong (Eds.), (pp. 175-184). Dordrecht, Netherlands: Kluwer Academic Publishers.

Morais, J., Cary, L., Alegria, J., \& Bertelson, P. (1979). Does awareness of speech as a sequence of phones arise spontaneously? Cognition, 7, 323-331.

Nascimento, M. F., Rivenc, P., \& Cruz, M. L. (1987). Portugues fundamental, metodos e documentos. Instituto Nacional de Investigatio Cientifica, Centro de Linguistica da Universidade de Lisboa.

Nyberg, L., McIntosh, A. R., Cabeza, R., Nilsson, L.-G., Houle, S., Habib, R., \& Tulving, E. (1996). Network analysis of positron emission tomography regional cerebral blood flow data: Ensemble inhibition during episodic memory retrieval. Journal of Neuroscience, 16, 3753-3759.

Pardo, J. V., Pardo, P. J., Janer, W., \& Raichle, M. E. (1990). The anterior cingulate cortex mediates processing selection in the Stroop attentional conflict paradigm. Proceedings of the National Academy of Sciences, U.S.A, 87, 256-259.

Patterson, K., \& Lambon Ralph, M. A. (1999). Selective disorders of reading? Current Opinion in Neurobiology 9, 235-239.

Patterson, K., \& Shewell, C. (1987). Speak and spell: Dissocations and word-class effects. In: S. G. Coltheart, G. Sartori \& R. Job (Eds.), The cognitive neuropsychology of language, (pp. 273-294). Hillsdale, NJ: Erlbaum.

Paulesu, E., Connelley, A., Frith, C. D., Friston, K. J., Heather, J., Meyers, R., Gadian, D. G., \& Frackowiak, R. S. J. (1995). Functional MR imaging, correlations with positron emission tomography: Initial experience using a cognitive activation paradigm on verbal working memory. Neuroimaging Clinics of North America, 5, 207-225.

Paulesu, E., Frith, C. D., \& Frackowiak, R. S. (1993). The neural correlates of the verbal component of working memory. Nature, 362, 342-344.

Paulesu, E., Frith, U., Snowling, M., Gallagher, A., Morton, J., Frackowiak, R. S. J., \& Frith, C. D. (1996). Is developmental dyslexia a disconnection syndrome? Evidence from PET scanning. Brain, 119, 143-157.

Petersen, S. E., \& Fiez, J. A. (1993). The processing of single words studied with positron emission tomography. Annual Review of Neurology, 16, 509-530.

Petersen, S. E., Fox, P. T., Posner, M. I., Mintun, M., \& Raichle, M. E. (1989). Functional imaging and language: Evidence from positron emission tomography. Journal of Cognitive Neuroscience, 1, 153-170.

Petersson, K. M., Nichols, T. E., Poline, J.-B., \& Holmes, A. P. (1999a). Statistical limitations in functional neuroimaging I: Noninferential methods and statistical models. Philosophical Transactions of the Royal Society of London, B 354, 1239-1260.

Petersson, K. M., Nichols, T. E., Poline, J.-B., \& Holmes, A. P. (1999b). Statistical limitations in functional neuroimaging II: Signal detection and statistical inference. Philosophical Transactions of the Royal Society of London, B 354, 1261-1282.

Petersson, K. M., Reis, A., Askelöf, S., Castro-Caldas, A., \& Ingvar, M. (1998). Differences in inter-hemispheric interactions between literate and illiterate subjects during verbal repetition. NeuroImage, 7, S217.

Petersson, K. M., Reis, A., Castro-Caldas, A., \& Ingvar, M. (1999c). Effective auditory-verbal encoding activates the left prefrontal and the medial temporal lobes: A generalization to illiterate subjects. NeuroImage, 10, 45-54.

Petrides, M. (1995). Functional organization of the human frontal cortex for mnemonic processing. Evidence from neuroimaging studies. Annals of the New York Academy of Science, 769, 85-96.

Petrides, M., Alivisatos, B., \& Evans, A. C. (1995). Functional activation of the human ventrolateral frontal cortex during mnemonic retrieval of verbal information. Pro- 
ceedings of the National Academy of Sciences, U.S.A., 92, 5803-5807.

Petrides, M., Alivisatos, B., Meyer, E., \& Evans, A. C. (1993). Functional activation of the human frontal cortex during the performance of verbal working memory tasks. Proceedings of the National Academy of Sciences, U.S.A., 90, 878-852.

Pinker, S. (1997). Words and rules in the human brain. Nature, 387, 547-548.

Pinker, S., \& Prince, A. (1989). Rules and connections in human language. In: R. G. M. Morris (Ed.), Parallel distributed processing: Implications for psychology and neurobiology, (pp. 182-199). Oxford: Clarendon Press.

Posner, M. I., \& Petersen, S. E. (1990). The attention system of the human brain. Annual Review of Neuroscience, 13, 25-42.

Posner, M. I., \& Raichle, M. E. (1994). Images of mind, New York: Scientific American Library.

Price, C. J., Moore, C. J., Humphreys, G. W., \& Wise, R. J. S. (1997). Segregating semantic from phonological processes during reading. Journal of Cognitive Neuroscience, 9, 919-931.

Price, C. J., Wise, R. J. S., Warburton, E. A., Moore, C. J., Howard, D., Patterson, K., Frackowiak, R. S. J., \& Friston, K. J. (1996). Hearing and saying: The functional neuro-anatomy of auditory word-processing. Brain, 119, 919-931.

Prince, A., \& Smolensky, P. (1997). Optimality: From neural networks to universal grammer. Science, 275, 1604-1610.

Raichle, M. E. (1994). Images of the mind: Studies with modern imaging techniques. Annual Review of Psychology, 45, 333-356.

Raichle, M. E., Fiez, J. A., Videen, T. O., MacLeod, A.-M. K., Pardo, J. V., Fox, P. T., \& Petersen, S. E. (1994). Practicerelated changes in human brain funtional anatomy during nonmotor learning. Cerebral Cortex, 4, 8-26.

Redington, M., \& Chater, N. (1997). Probabilistic and distributional approaches to language acquisition. TICS, 1, 273-281.

Reis, A., \& Castro-Caldas, A. (1997). Illiteracy. A bias for cognitive development. Journal of the International Neuropsychological Society, 3, 444-450.

Rumelhart, D., \& McClelland, J. L. (1986). Parallel distributed processing: Explorations in the microstructures of cognition. Cambridge: MIT Press.

Salmon, E., Van der Linden, M., Collette, F., Delfiore, G., Maquet, P., Degueldre, C., Luxen, A., \& Franck, G. (1996). Re- gional brain activity during working memory tasks. Brain, 119, 1617-1625.

Schmahmann, J. D. (1996). From movement to thought: Anatomical substrates of the cerebellar contribution to cognitive processing. Human Brain Mapping, 4, 174-198.

Seidenberg, M. (1995). Linguistic morphology. In: M. A. Arbib (Ed.), (pp. 546-549). Cambridge: MIT Press.

Seidenberg, M., \& McClelland, J. L. (1989). A distributed, developmental model of word recognition and naming. Psychology Review, 96, 523-568.

Shastri, L. (1995). Structured connectionist models. In: M. A. Arbib (Ed.), The handbook of brain theory and neural networks, (pp. 949-952). Cambridge: MIT Press.

Shastri, L., \& Ajjanagadde, V. (1993). From simple associations to systematic reasoning: A connectionist encoding of rules, variables, and dynamic bindings using temporal synchrony. Behavioural Brain Science, 16, 417-494.

Shepherd, G. M. (1997). The synaptic organization of the brain, 4th ed. New York: Oxford University Press.

Smolensky, P. (1988). On the proper treatment of connectionism. Behavioural Brain Science, 11, 1-74.

Snowling, M., Hulme, C., \& Nation, K. (1997). A connectionist perspective on the development of reading skills in children. TICS, 1, 88-91.

Talairach, J., \& Tournoux, P. (1988). Co-planar stereotaxic atlas of the human brain. Stuttgart: George Thieme Verlag.

Vandenberghe, R., Price, C., Wise, R., Josephs, O., \& Frackowiak, R. S. J. (1996). Functional anatomy of a common semantic system for words and pictures. Nature, 383, 254-256.

Vogt, B. A., Finch, D. M., \& Olson, C. R. (1992). Functional heterogeneity in cingulate cortex: The anterior executive and posterior evaluative regions. Cerebral Cortex, 2, 435-443.

Wechsler, A. F. (1976). Crossed aphasia in an illiterate dextral. Brain and Language, 3, 164-172.

Wienhard, K., Dahlbom, M., Eriksson, L., Michel, C., Bruckbauer, T., Pietrzyk, U., \& Heiss, W.-D. (1994). The ECAT EXACT HR: Performance of a new high resolution positron scanner. Journal of Computer Assisted Tomography, 18, 110-118.

Wise, R. J. S., Chollet, F., Hadar, U., Friston, K., Hoffner, E., \& Frackowiak, R. S. J. (1991). Distribution of cortical neural networks involved in word comprehension and word retrieval. Brain, 114, 1803-1817. 